\title{
Cluster-enhanced $X-\mathrm{O}_{2}$ photochemistry $\left(X=\mathrm{CH}_{3} \mathrm{I}, \mathrm{C}_{3} \mathrm{H}_{6}, \mathrm{C}_{6} \mathrm{H}_{12}\right.$, and $\left.\mathrm{Xe}\right)$
}

\author{
Alexey V. Baklanov, Georgii A. Bogdanchikov, and Konstantin V. Vidma \\ Institute of Chemical Kinetics and Combustion, Institutskaja Street 3, Novosibirsk 630090 Russia \\ and Novosibirsk State University, Pirogova St. 2, Novosibirsk 630090, Russia \\ Dmitri A. Chestakov and David H. Parker \\ Institute for Molecules and Materials, Radboud University Nijmegen, Toernooiveld, 6525 ED Nijmegen, \\ The Netherlands
}

(Received 29 November 2006; accepted 25 January 2007; published online 28 March 2007)

\begin{abstract}
The effect of a local environment on the photodissociation of molecular oxygen is investigated in the van der Waals complex $\mathrm{X}-\mathrm{O}_{2}\left(\mathrm{X}=\mathrm{CH}_{3} \mathrm{I}, \mathrm{C}_{3} \mathrm{H}_{6}, \mathrm{C}_{6} \mathrm{H}_{12}\right.$, and $\left.\mathrm{Xe}\right)$. A single laser operating at wavelengths around $226 \mathrm{~nm}$ is used for both photodissociation of the van der Waals complex and simultaneous detection of the $\mathrm{O}\left({ }^{3} P_{J}, J=2,1,0\right)$ atom photoproduct via $(2+1)$ resonance enhanced multiphoton ionization. The kinetic energy distribution (KED) and angular anisotropy of the product $\mathrm{O}$ atom recoil in this dissociation are measured using the velocity map imaging technique configured for either full ("crush") or partial ("slice") detection of the three-dimensional $\mathrm{O}\left({ }^{3} P_{J}\right)$ atom product Newton sphere. The measured KED and angular anisotropy reveal a distinct difference in the mechanism of $\mathrm{O}$ atom generation from an $\mathrm{X}-\mathrm{O}_{2}$ complex compared to a free $\mathrm{O}_{2}$ molecule. The authors identify two one-photon excitation pathways, the relative importance of which depends on IPx, the ionization potential of the X partner. One pathway, observed for all complexes independent of IPx, involves a direct transition to the perturbed covalent state $\mathrm{X}-\mathrm{O}_{2}\left(A^{\prime 3} \Delta_{u}\right)$ with excitation localized on the $\mathrm{O}_{2}$ subunit. The predominantly perpendicular character of this channel relative to the laser polarization detection, together with data on the structure of the complex, allows us to confirm that $\mathrm{X}$ partner induced admixing of an $\mathrm{X}^{+}-\mathrm{O}_{2}^{-}$charge transfer $(\mathrm{CT})$ state is the perturbing factor resulting in the well-known enhancement of photoabsorption within the Herzberg continuum of molecular oxygen. The second excitation pathway, observed for $\mathrm{X}-\mathrm{O}_{2}$ complexes with $\mathrm{X}$ $=\mathrm{CH}_{3} \mathrm{I}$ and $\mathrm{C}_{3} \mathrm{H}_{6}$, involves direct excitation into the ${ }^{3}\left(\mathrm{X}^{+}-\mathrm{O}_{2}^{-}\right)$CT state of the complex. The subsequent photodissociation of this $\mathrm{CT}$ state by the same laser pulse gives rise to the superoxide anion $\mathrm{O}_{2}^{-}$, which then photodissociates, providing fast $(0.69 \mathrm{eV}) \mathrm{O}$ atoms with a parallel image pattern. Products from the photodissociation of singlet oxygen $\mathrm{O}_{2}\left(b^{1} \Sigma_{g}^{+}\right)$are also observed when the $\mathrm{CH}_{3} \mathrm{I}-\mathrm{O}_{2}$ complex was irradiated. Potential energy surfaces (PES) for the ground and relevant excited states of the $\mathrm{X}-\mathrm{O}_{2}$ complex have been constructed for $\mathrm{CH}_{3} \mathrm{I}-\mathrm{O}_{2}$ using the results of CASSCF calculations for the ground and CT states of the complex as well as literature data on PES of the subunits. These model potential energy surfaces allowed us to interpret all of the observed $\mathrm{O}\left({ }^{3} P_{J}\right)$ atom production channels. (C) 2007 American Institute of Physics.
\end{abstract}

[DOI: $10.1063 / 1.2710268]$

\section{INTRODUCTION}

Molecular oxygen $\mathrm{O}_{2}$ is essentially transparent to light with wavelengths longer than $200 \mathrm{~nm}$. Despite this fact, $\mathrm{O}_{2}$ plays a key role in many important light-induced processes including the chemistry of the atmosphere, oxidative organic photochemistry, as well as in oxygen assisted photobiochemistry in organisms exposed to solar radiation. In the earth's atmosphere the main fraction of ground-state $\mathrm{O}\left({ }^{3} P_{J}\right)$ oxygen atoms arise from dissociation of molecular oxygen following absorption of ultraviolet (UV) radiation in the 200-242 nm region known as the $\mathrm{O}_{2}$ Herzberg continuum, which is composed of three overlapping transitions from the $X^{3} \Sigma_{g}^{-}$ground state to the excited $A^{3} \Sigma_{u}^{+}, c{ }^{1} \Sigma_{u}^{-}$, and $A^{\prime}{ }^{3} \Delta_{u}$ states. All three transitions, named Herzberg I, II, and III, respectively, are optically forbidden, resulting in a very low absorption cross section which is governed mainly by the Herzberg I system. The total cross section of the Herzberg continuum is less than that of an allowed transition by a factor of $10^{6}-10^{7}$. The subsequent photochemistry following the excitation of $\mathrm{O}_{2}$ in the Herzberg continuum has been recently reviewed. ${ }^{1}$

UV absorption is dramatically enhanced when $\mathrm{O}_{2}$ is perturbed by nearby molecules in the gas or condensed phase. This enhanced absorption, which takes place in the Herzberg continuum and also in the discrete Herzberg bands at longer wavelengths $(>242 \mathrm{~nm})$ in the UV, has been studied by many groups and reviewed by Blake and $\mathrm{McCoy}^{2}$ and recently by Koda and Sugimoto. ${ }^{3}$ According to existing data in both the gas phase and condensed medium, the Herzberg III transition $A^{\prime}{ }^{3} \Delta_{u} \leftarrow X^{3} \Sigma_{g}^{-}$is the dominant contributor to enhanced absorption. ${ }^{2-8}$ The perturbing environment causes not only an enhancement of the Herzberg III absorption but also in some cases the appearance of charge-transfer (CT) bands which were observed for the first time by Evans in oxygenated solvents. ${ }^{9}$ In the gas phase, the intermolecular interac- 
tion responsible for the enhanced absorption takes place in transient collision complexes of $\mathrm{O}_{2}$ with a nearby $\mathrm{X}$ molecule. Under atmospheric conditions, pressure-dependent collision-induced absorption within the Herzberg continuum is quite important and becomes comparable with pressureindependent absorption of free $\mathrm{O}_{2}$ molecules. ${ }^{2}$ The relative strength of the collision-induced $\mathrm{O}_{2}$ absorption enhancement has been studied for many foreign gases X.,10,11 On the basis of measurements of pressure-dependent absorption in pure oxygen, Shardanand estimated the value of the absorption cross section of the $\mathrm{O}_{2}-\mathrm{O}_{2}$ pair to be about 1000 times higher than the cross section for free $\mathrm{O}_{2}$ molecules. ${ }^{12}$

Studies of a wide range of $\mathrm{X}$ partners in an $\mathrm{X}-\mathrm{O}_{2}$ collision pair ${ }^{4,10,11}$ have shown that intermolecular interactions can enhance the $\mathrm{O}_{2}$ absorption by values up to $10^{6}-10^{7}$. These studies have shown that the ionization potential of the $\mathrm{X}$ partner, $\mathrm{IP}_{\mathrm{X}}$, is the main factor determining the degree of enhancement in the UV region of the spectrum. For sufficiently low $\operatorname{IP}_{\mathrm{X}}(<9.5 \mathrm{eV})$, the enhancement can be due to direct absorption to an $\mathrm{X}-\mathrm{O}_{2} \mathrm{CT}$ state. ${ }^{4,11}$ For $9.5 \mathrm{eV}$ $\leqslant \mathrm{IP}_{\mathrm{X}} \leqslant 11 \mathrm{eV}$ the long-wavelength wing of the CT band is believed to contribute along with the Herzberg III absorption and for IP $(\mathrm{X})>11 \mathrm{eV}$, only the Herzberg III induced absorption takes place, and its intensity increases with decreasing $\mathrm{IP}(\mathrm{X})$. In this work, we study the influence of the $\mathrm{X}$ partners methyl iodide $\mathrm{CH}_{3} \mathrm{I}$, propylene $\mathrm{C}_{3} \mathrm{H}_{6}$, cyclohexane $\mathrm{C}_{6} \mathrm{H}_{12}$, and xenon $\mathrm{Xe}$ on the UV absorption and photochemistry of $\mathrm{O}_{2}, \quad$ where $\operatorname{IP}\left(\mathrm{CH}_{3} \mathrm{I}\right)=9.54 \mathrm{eV}, \quad \operatorname{IP}\left(\mathrm{C}_{3} \mathrm{H}_{6}\right)=9.73 \mathrm{eV}$, $\operatorname{IP}\left(\mathrm{C}_{6} \mathrm{H}_{12}\right)=9.88 \mathrm{eV}$, and $\operatorname{IP}(\mathrm{Xe})=12.13 \mathrm{eV}$, while $\operatorname{IP}\left(\mathrm{O}_{2}\right)$ $=12.07 \mathrm{eV}$.

Van der Waals complexes offer an alternative means for studying local environment effects in the gas phase. Compared to a transient collision complex, they provide a more limited sampling of intermolecular distance and relative geometry. $\mathrm{X}-\mathrm{O}_{2}$ van der Waals complexes have been the subject of previous studies ${ }^{13-16}$ of cluster-induced absorption and photodissociation phenomena. Photoexcitation into the Herzberg continuum provides sufficient energy for dissociation of the $\mathrm{O}_{2}$ molecule in the complex. To elucidate the mechanism giving rise to the product $\mathrm{O}$ atoms, DeBoer et $a$ al $^{13,14}$ and Parsons and Chandler ${ }^{15}$ studied the $\mathrm{O}$ fragment energy distribution and angular anisotropy. DeBoer et al. applied kinetic-energy-resolved time-of-flight mass spectrometry while Parsons and Chandler used velocity mapped ion imaging. Both groups interpreted their results as being due to direct excitation of the complex into a charge-transfer state.

Here, we study the photodissociation of $\mathrm{X}-\mathrm{O}_{2}$ van der Waals complexes using standard velocity map imaging ${ }^{17}$ as well as our recent slicing variant. ${ }^{18}$ The use of slicing has allowed us to improve the quality of our $\mathrm{X}-\mathrm{O}_{2}$ image, and this has turned out to be crucial for identification of the photodissociation pathways giving rise to $\mathrm{O}\left({ }^{3} P_{J}\right)$ atoms. The main features of the potential energy surface (PES) of the $\mathrm{CH}_{3} \mathrm{I}-\mathrm{O}_{2}$ complex in the ground and excited states has also been calculated with the use of $a b$ initio as well as literature data. The results obtained have allowed us to elucidate the nature of the electronic state providing the absorption enhancement in $\mathrm{X}-\mathrm{O}_{2}$ complexes.

\section{EXPERIMENT}

Our velocity map imaging setup has been described in detail elsewhere. ${ }^{17}$ The main feature of this ion imaging $\operatorname{apparatus}^{19}$ is an electrostatic lens system using open electrodes for extracting nascent ions from the photoionization region through a time-of-flight region towards a twodimensional (2D) spatial detector, which is gated at the proper arrival time for mass selection. The electrostatic lens is set to project all ions of the same velocity to the same point on the 2D detector, independent of their position of formation (velocity focusing condition). In "conventional" velocity map imaging, ${ }^{17}$ the imaging lens voltage is permanently applied to the electrodes. The ratio of the voltages applied to the repeller and extractor electrodes is adjusted in order to provide velocity focusing conditions. This condition is fulfilled nearly simultaneously with time focusing, i.e., when all ions of the same mass arrive at the detector almost at the same time. The images obtained by this method are called crushed images. Time focusing ("crushing") is optimal when the ion cloud is very small at the beginning of the extraction, and when the nascent velocity of the ion is also small. Large ion cloud diameters and high ion velocities result in imperfect crushing.

Slicing of the image is possible without modifying the velocity map imaging setup, as described in detail by Chestakov et al. ${ }^{18}$ In this method photodissociation and photoionization occur in field-free conditions, and voltage is applied to the repeller and extractor electrodes around a microsecond after the formation of ions. This time delay allows the ion cloud to expand sufficiently before the beginning of the extraction. Since extraction starts when the ions are dispersed in the space, the velocity focusing and the time focusing conditions are no longer fulfilled simultaneously. The voltage is adjusted in order to provide velocity focusing, and ions of the same mass arrive at the detector over an extended period of time (up to $\sim 400 \mathrm{~ns}$ ) depending on the projection of their initial speed on the axis perpendicular to the detector. The detector is switched on for a short period of time $(\sim 15 \mathrm{~ns})$ at the proper moment in order to record the center slice of the ion cloud. In this case the obtained image should be roughly equivalent to a slice through the three-dimensional speed and angular distribution as obtained from inversion of the crushed image by means of the BASEX inversion program ${ }^{20}$

A molecular beam generated by a pulsed solenoid valve (general valve) directed parallel to the TOF axis passes through a $2 \mathrm{~mm}$ skimmer mounted $20 \mathrm{~mm}$ downstream from the nozzle. At an additional $100 \mathrm{~mm}$ downstream the molecular beam passes through a $1 \mathrm{~mm}$ hole in the repeller electrode and enters the region between the repeller and extractor electrodes, where photoexcitation takes place. Tunable UV radiation ( $\sim 1 \mathrm{~mJ} /$ pulse, $5 \mathrm{~ns}$ pulse duration) provided by frequency doubling the output of a neodymiumdoped yttrium aluminum garnet laser pumped dye laser (coumarin 47) was focused at or near the molecular beam using a $20 \mathrm{~cm}$ focal length planoconvex lens. Experiments were performed at three wavelengths used for $(2+1)$ reso- 
nance enhanced multiphoton ionization (REMPI) of $\mathrm{O}\left({ }^{3} P_{J}\right)$ atoms $(226.233,226.059$, and $225.656 \mathrm{~nm}$ for $J=0,1,2$, respectively).

The gas mixtures for making $\mathrm{CH}_{3} \mathrm{I}-\mathrm{O}_{2}$ clusters were prepared by flowing a mixture of $\mathrm{O}_{2}(5 \%)$ and $\mathrm{Ar}(95 \%)$ through a glass bubbler containing liquid methyl iodide at a fixed temperature. Experiments with helium as a carrier gas have been also carried out. The vapor pressure of methyl iodide was controlled by keeping the liquid at a chosen temperature using a slush bath. Two kinds of slush were used: acetonitrile with the temperature of $-43.9{ }^{\circ} \mathrm{C}$ and chloroform $\left(-63.4{ }^{\circ} \mathrm{C}\right)$. These provide a methyl iodide vapor pressure of 11.5 and 2.5 Torr, respectively. The total gas pressure before the nozzle was typically about 2 bar, which yields a gas mixture composition of $\mathrm{CH}_{3} \mathrm{I}(1 \%$ or $0.2 \%)+\mathrm{O}_{2}(5 \%)$ + Ar. Variation of the $\mathrm{CH}_{3} \mathrm{I}$ content from $0.2 \%$ to $1 \%$, variation of the $\mathrm{O}_{2}$ content from $5 \%$ to $15 \%$, and changing the carrier gas from $\mathrm{Ar}$ to $\mathrm{He}$ did not change the $\mathrm{O}$ atom image arising from photodissociation of the $\mathrm{CH}_{3} \mathrm{I}-\mathrm{O}_{2}$ complex. For these reasons we believe that predominantly 1:1 clusters are studied.

The gas mixture for experiments with $\mathrm{C}_{6} \mathrm{H}_{12}-\mathrm{O}_{2}$ clusters was prepared in a similar manner and its composition was $\mathrm{C}_{6} \mathrm{H}_{12}(0.4 \%)+\mathrm{O}_{2}(5 \%)+$ Ar. Gas mixtures for experiments with $\mathrm{C}_{3} \mathrm{H}_{6}-\mathrm{O}_{2}$ and $\mathrm{Xe}-\mathrm{O}_{2}$ clusters were prepared in a stainless steel bottle with $\mathrm{C}_{3} \mathrm{H}_{6}(2 \%)+\mathrm{O}_{2}(5 \%)+\mathrm{Ar}$, and $\mathrm{Xe}(1 \%)+\mathrm{O}_{2}(5 \%)+\mathrm{Ar}$, respectively.

Images from the photoexcitation of free $\mathrm{O}_{2}$ molecules were recorded in order to provide calibration of the fragment kinetic energy and for comparison with the cluster experiments. Two signals were used for image calibration; onephoton dissociation

$$
\mathrm{O}_{2} \stackrel{h \nu}{\longrightarrow} \mathrm{O}\left({ }^{3} P_{J}\right)+\mathrm{O}\left({ }^{3} P_{J}\right)
$$

and two-photon dissociation

$$
\mathrm{O}_{2} \stackrel{2 h \nu}{\longrightarrow} \mathrm{O}\left({ }^{3} P_{J}\right)+\mathrm{O}\left({ }^{1} D_{2}\right) \text {. }
$$

At the $\mathrm{O}\left({ }^{3} P_{2}\right)$ detection wavelength $(225.656 \mathrm{~nm})$ the portion of the image corresponding to one-photon dissociation is a superposition of three channels: $\mathrm{O}\left({ }^{3} P_{2}\right)+\mathrm{O}\left({ }^{3} P_{2}\right), \mathrm{O}\left({ }^{3} P_{2}\right)$ $+\mathrm{O}\left({ }^{3} P_{1}\right)$, and $\mathrm{O}\left({ }^{3} P_{2}\right)+\mathrm{O}\left({ }^{3} P_{0}\right)$, where the $\mathrm{O}$ atom kinetic energy release $\left(E_{t}\right)$ is $0.189,0.179$, and $0.175 \mathrm{eV}$, respectively. These quantities are calculated using $E_{t}=\left(h v-D_{0}\left(\mathrm{O}_{2}\right)\right.$ $\left.-E_{\text {int }}\left(\mathrm{O}\left({ }^{3} P_{J}\right)\right)\right) / 2$, where $h v=5.494 \mathrm{eV}, D_{0}\left(\mathrm{O}_{2}\right)=5.117 \mathrm{eV}$, ${ }^{21}$ and $E_{\text {int }}\left(\mathrm{O}\left({ }^{3} P_{J}\right)\right)$ is the internal energy of the $\mathrm{O}\left({ }^{3} P_{J}\right)$ state. These three channels are not resolved for the conditions used and appear as a single ring in the image. For calibration we assumed that the maximum of the intensity of this ring corresponds to a total kinetic energy of $0.184 \mathrm{eV}$ - the average value calculated assuming a 1:3:5 statistical ${ }^{3} P_{0}:{ }^{3} P_{1}:{ }^{3} P_{2}$ branching ratio. The two-photon dissociation ring corresponds to an $\mathrm{O}$ atom kinetic energy of $1.955 \mathrm{eV}$. An essentially identical $\mathrm{O}\left({ }^{3} P\right)$ image was obtained when using $2 \% \mathrm{O}_{2}$ in $\mathrm{Ar}$ at 2 bar and 2 bar of pure $\mathrm{O}_{2}$. We were not able to obtain an image indicating $\mathrm{O}_{2}-\mathrm{Ar}$ formation, or an image indicating $\mathrm{O}_{2}-\mathrm{O}_{2}$ formation, even when using similar conditions to those reported by DeBoer et al. ${ }^{14}$
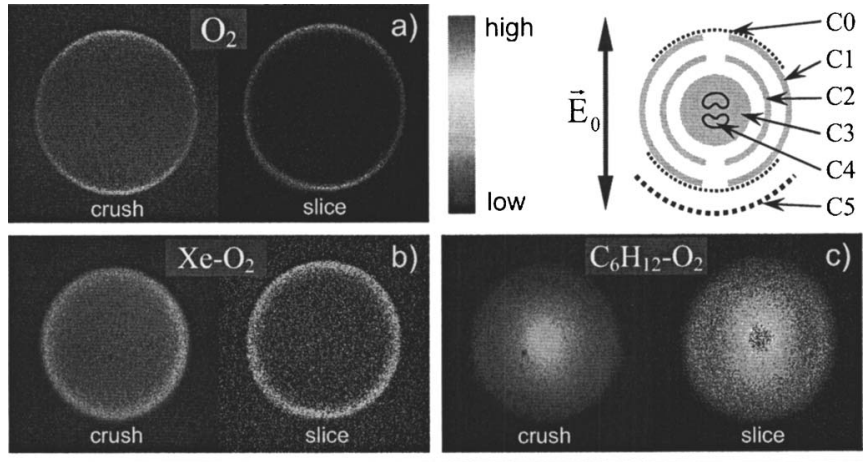

$\mathrm{C}_{6} \mathrm{H}_{12}-\mathrm{O}_{2}$

c)
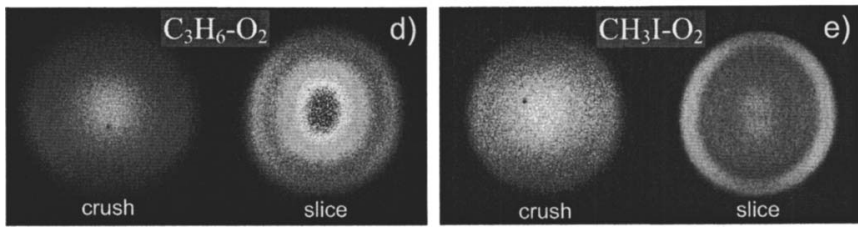

FIG. 1. Raw velocity mapped ion images of $\mathrm{O}\left({ }^{3} P_{2}\right)$ atoms with low kinetic energy produced by the photodissociation of free $\mathrm{O}_{2}$ molecules and by $\mathrm{X}-\mathrm{O}_{2}$ van der Waals complexes at $225.656 \mathrm{~nm}$ : crushed (left) and sliced (right) images of (a) free $\mathrm{O}_{2}$, (b) $\mathrm{Xe}-\mathrm{O}_{2}$, (c) $\mathrm{C}_{6} \mathrm{H}_{12}-\mathrm{O}_{2}$, (d) $\mathrm{C}_{3} \mathrm{H}_{6}-\mathrm{O}_{2}$, and (e) $\mathrm{CH}_{3} \mathrm{I}-\mathrm{O}_{2}$. Signal from excess free $\mathrm{O}_{2}$ has not been subtracted from the images. In the upper right corner the enumerated channels $\mathrm{C} 1-\mathrm{C} 5$ observed in the images (Figs. 1 and 2) of the studied complexes as well as from free $\mathrm{O}_{2}$ molecules $(\mathrm{C} 0)$ are schematically shown. Vector $\mathbf{E}_{0}$ shows the direction of the polarization of the exciting radiation. For the $\mathrm{CH}_{3} \mathrm{I}-\mathrm{O}_{2}$ and $\mathrm{C}_{3} \mathrm{H}_{6}-\mathrm{O}_{2}$ complexes, a high kinetic energy channel $\mathrm{C} 5$ was also observed (see Fig. 2).

For the $\mathrm{Xe}-\mathrm{O}_{2}$ system an image due to photodissociation of free $\mathrm{O}_{2}$ with the same $\mathrm{O}_{2}$ percentage in Ar, but without $\mathrm{Xe}$ in the expansion mixture, was subtracted before Abel inversion of the cluster image. For the other three complexes this subtraction was not necessary because the relative contribution due to photodissociation of free $\mathrm{O}_{2}$ was negligible.

\section{RESULTS}

Raw images of $\mathrm{O}\left({ }^{3} P_{J}\right)$ atoms arising from the photodissociation of the $\mathrm{X}-\mathrm{O}_{2}$ complexes $\left(\mathrm{X}=\mathrm{CH}_{3} \mathrm{I}, \mathrm{C}_{3} \mathrm{H}_{6}, \mathrm{C}_{6} \mathrm{H}_{12}\right.$, $\mathrm{Xe})$ are presented in Figs. 1 and 2 for both crush and slicing conditions. For comparison, an image from photodissociation of free $\mathrm{O}_{2}$ is shown in Fig. 1(a). All of the complexes showed a strong increase in the $\mathrm{O}\left({ }^{3} P\right)$ atom yield as compared with photodissociation of free $\mathrm{O}_{2}$, in spite of the low relative concentration of $\mathrm{X}$ in the expanded mixture. For example, the $\mathrm{CH}_{3} \mathrm{I}-\mathrm{O}_{2}$ enhancement is estimated to be at least
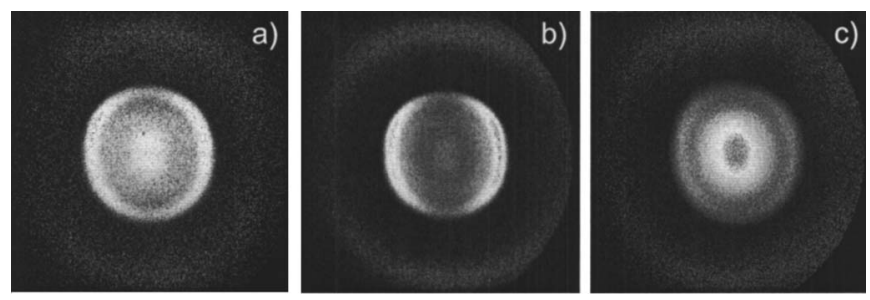

FIG. 2. Raw slice images of $\mathrm{O}\left({ }^{3} P_{J}\right)$ atoms produced in the photodissociation of the van der Waals complexes (a) $\mathrm{CH}_{3} \mathrm{I}-\mathrm{O}_{2}$ with $\mathrm{O}\left({ }^{3} P_{2}\right)$ probed, (b) $\mathrm{CH}_{3} \mathrm{I}-\mathrm{O}_{2}$ with $\mathrm{O}\left({ }^{3} P_{0}\right)$ probed, and (c) $\mathrm{C}_{3} \mathrm{H}_{6}-\mathrm{O}_{2}$ with $\mathrm{O}\left({ }^{3} P_{2}\right)$ probed. Images (a) and (c) are the same as the sliced images on Figs. 1(e) and 1(d), respectively, but with a larger part of the image shown to include the outer ring. This outer ring for all of the images has been artificially enhanced in intensity by a factor of $5-10$ for better visibility in this figure. 
a factor of 350 and is probably much higher, but the limited dynamic range of the detector prohibits a more accurate estimation. Images taken using $\mathrm{O}^{3} P_{1}$ and $\mathrm{O}^{3} P_{0}$ detection were similar to the $\mathrm{O}^{3} P_{2}$ images for all the clusters studied and followed the total intensity ratio $J=0: 1: 2 \sim 1: 2.5: 8$, which is nearly the same yield ratio found for free $\mathrm{O}_{2}{ }^{22}$ $J$-dependent differences observed in the images are discussed later in this section.

The slice images, while slightly distorted, show considerably more detail than the crush images. A $1.3 \mu$ s delay was used between ionization and extraction when obtaining the slice images. Ion trajectory simulations for our conditions show that the degree of slicing is not high at this time delay. Longer time delays result in better slicing but also larger distortions because the ion cloud grows too large for ideal electrostatic lens functioning ( $>10 \%$ of the annular electrode opening is used). As the degree of slicing is moderate, the improvement in the image quality with slicing must be also due to the experimental approach. In $1.3 \mu \mathrm{s}$ the ion packet moves $\sim 1 \mathrm{~mm}$ downstream with the molecular beam velocity. The repeller extractor ratio is adjusted for the extraction position, meaning only those molecules moving with the beam velocity are properly velocity mapped. Under the crush condition (velocity mapping at zero time delay) the image appears to contain a rather isotropic $\mathrm{O}\left({ }^{3} P_{2}\right)$ signal not moving at the molecular beam velocity. This "background" is not from free $\mathrm{O}_{2}$ because of the low absorption cross section. Possible sources could be ionization of the cluster beam or thermal $\mathrm{O}_{2}$ by the initial electrons released in the REMPI process, warmer clusters that have suffered a nonfatal collision, or interaction of the ion package with the rather intense molecular beam on the way to the detector. The outside edge of the ion spheres grows to a $\sim 2 \mathrm{~mm}$ radius after the $1.3 \mu \mathrm{s}$ time delay, thus the main part of the ion packet under slicing conditions is out of the molecular beam. Because of image distortion and low degree of slicing a quantitative analysis of the sliced images is not attempted here.

Our crushed $\mathrm{C}_{6} \mathrm{H}_{12}-\mathrm{O}_{2}$ image, shown in Fig. 1(c), agrees qualitatively with the image obtained by Parsons and Chandler in Ref. 15. Our sliced images, however, reveals four different $\mathrm{O}$ fragment groups of signal in the case of the $\mathrm{CH}_{3} \mathrm{I}-\mathrm{O}_{2}$ complex photodissociation, three for $\mathrm{C}_{3} \mathrm{H}_{6}-\mathrm{O}_{2}$, two for $\mathrm{C}_{6} \mathrm{H}_{12}-\mathrm{O}_{2}$, and only one group for the $\mathrm{Xe}-\mathrm{O}_{2}$ complex. These signal groups (labeled channels C1-C5 in Fig. 1) are characterized by a specific $\mathrm{O}$ atom recoil velocity distribution and angular anisotropy and are indicators of different channels contributing to the dissociation of the complex. Channels $\mathrm{C} 1-\mathrm{C} 4$ give rise to free $\mathrm{O}$ atoms with a kinetic energy $E_{t 1-4}$ lower than that of channel $\mathrm{C} 0$, observed for one-photon dissociation of free $\mathrm{O}_{2}$, which has a value of $E_{t 0}=0.184 \mathrm{eV} . \mathrm{O}\left({ }^{3} P_{2}\right)$ speed distributions extracted from the images from Fig. 1 are shown in Fig. 3. All four complexes contain $\mathrm{O}$ atom signals from channel $\mathrm{C} 1$ (labeled in the upper right corner of Fig. 1) and have a kinetic energy value close to $E_{t 0}$. Angular distributions have been fitted with the equation $f(\theta)=A\left(1+\beta\left(\frac{3}{2} \cos ^{2} \theta-\frac{1}{2}\right)\right)$, where $\theta$ is the angle between the recoil and the laser polarization direction, and $\beta$ is the anisotropy parameter. ${ }^{19}$ The $\beta$ values obtained for channel $\mathrm{C} 1$ are also indicated in Fig. 3 and are negative for all four of the complexes studied. This implies that the transition dipole moment for photoexcitation giving rise to channel $\mathrm{C} 1$ is preferentially perpendicular to the $\mathrm{O}-\mathrm{O}$ bond in the complex. Another perpendicular channel, C2, with a lower and broad $E_{t 2}$ value is visible in the sliced image for the $\mathrm{CH}_{3} \mathrm{I}-\mathrm{O}_{2}$ complex [Fig. 1(e)]. A multi-Gaussian fit of the sliced image profile allows us to estimate the difference between the energy of $\mathrm{C} 1$ and $\mathrm{C} 2, E_{t 1}-E_{t 2}=530 \pm 100 \mathrm{~cm}^{-1}$. The lowest kinetic energy channel $\mathrm{C} 4\left(\sim 80-160 \mathrm{~cm}^{-1}\right)$ observed for the $\mathrm{CH}_{3} \mathrm{I}-\mathrm{O}_{2}$ complex has a small but wellpronounced positive anisotropy [Fig. 1(e)] corresponding to a parallel excitation transition. This channel is noticeably weaker with $\mathrm{O}^{3} P_{1,0}$ detection compared to $\mathrm{O}^{3} P_{2}$ detection [Figs. 2(a) and 2(b)]. For the complexes $\mathrm{C}_{6} \mathrm{H}_{12}-\mathrm{O}_{2}$ and $\mathrm{C}_{3} \mathrm{H}_{6}-\mathrm{O}_{2}$ the signal at the middle of the images [Figs. 1(c) and 1(d)], labeled channel C3, is essentially isotropic. The parallel channel $\mathrm{C} 5$ observed for complexes $\mathrm{CH}_{3} \mathrm{I}-\mathrm{O}_{2}$ and $\mathrm{C}_{3} \mathrm{H}_{6}-\mathrm{O}_{2}$ (outer rings observed in Fig. 2) corresponds to $\mathrm{O}\left({ }^{3} P_{2}\right)$ atoms with a high kinetic energy $E_{t 5}=0.69 \pm 0.04$ and $0.68 \mathrm{eV}$, respectively. The contribution of this channel was found to be about $3 \%$ of the integral $\mathrm{O}$ atom yield for the $\mathrm{CH}_{3} \mathrm{I}-\mathrm{O}_{2}$ complex and about $2 \%$ for the $\mathrm{C}_{3} \mathrm{H}_{6}-\mathrm{O}_{2}$ complex. Channel 5 is most observable using $\mathrm{O}^{3} P_{0}$ detection, in part due to a lower contribution of signal from two-photon dissociation which overlaps this fragment channel, but also due to a higher $\mathrm{O}^{3} P_{J}, J=0$ yield for Channel 5 compared to the other channels.

We note that in the earlier studies of the $\mathrm{C}_{3} \mathrm{H}_{6}-\mathrm{O}_{2}$ (Ref. 14) and $\mathrm{C}_{6} \mathrm{H}_{12}-\mathrm{O}_{2}$ (Ref. 15) complexes one-dimensional (1D) and 2D velocity data were analyzed and were concluded to belong to a single, isotropic channel. These observations correspond well with our channel C3 but we observe, especially in the sliced images, a more complex picture including several extra channels. Our experimental results for the $\mathrm{C}_{3} \mathrm{H}_{6}-\mathrm{O}_{2}$ complex agree nearly quantitatively with the data of Ref. 14, as shown in the Appendix. Regarding the results of Ref. 15, we point out that the high apparatus sensitivity $^{23}$ and background suppression from slicing has effectively improved the resolution of the images, allowing us to visualize more product channels.

We have carried out a calculation using GAUSSIAN 98 for the structure and binding energy of the $\mathrm{CH}_{3} \mathrm{I}-\mathrm{O}_{2}$ van der Waals complex in order to characterize its most stable isomers. The approach was similar to that used for the dimer of methyl iodide. ${ }^{24}$ An extended basis set with the addition of polarization and diffuse functions has been used. For carbon, hydrogen, and oxygen atoms, the aug-cc-pVTZ basis functions suggested by Dunning ${ }^{25}$ have been used. For iodine atoms SDB-aug-cc-pVTZ basis functions elaborated by Martin and Sunderman ${ }^{26}$ have been applied. These last functions in conjunction with a relativistic core polarization potential suggested by Bergner et al. ${ }^{27}$ have been taken from the online version. ${ }^{28}$ The GAUSSIAN 98 package ${ }^{29}$ has been used. The structure parameters have been obtained as a result of the full optimization at the MP2 level. The binding energy $\left(E_{\text {bind }}\right)$ has been calculated at MP4(SDTQ) $\|$ MP2 level with taking into account the basis set superposition error by the counterpoise method and zero-point energy, calculated within MP2 approach for optimized molecular structures. 

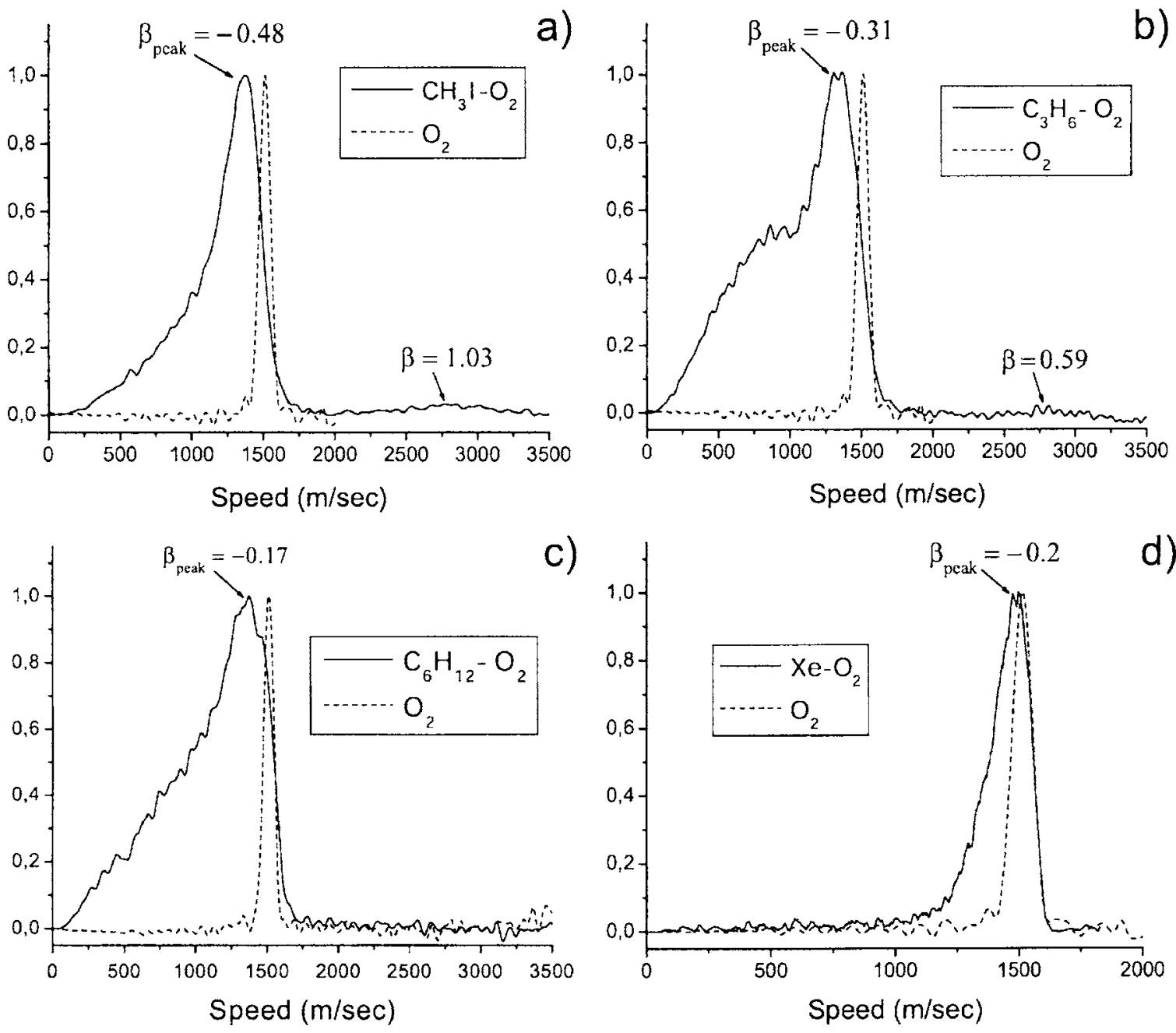

FIG. 3. Speed distributions of $\mathrm{O}\left({ }^{3} P_{2}\right.$ ) atoms arising from the photodissociation of (a) $\mathrm{CH}_{3} \mathrm{I}-\mathrm{O}_{2}$, (b) $\mathrm{C}_{3} \mathrm{H}_{6}-\mathrm{O}_{2}$, (c) $\mathrm{C}_{6} \mathrm{H}_{12}-\mathrm{O}_{2}$, and (d) Xe-O distribution for $\left.\mathrm{O}^{3} \mathrm{P}_{2}\right)$ atoms from free $\mathrm{O}_{2}$ molecules is also presented for comparison. The distributions are derived by inversion of the crushed velocity map images. The anisotropy parameters taken at the maxima of the distributions are shown on the images and denoted as $\beta_{\text {peak }}$. The anisotropy of the channel C5 is also shown in Figs. 3(a) and 3(b).

Calculated $E_{\text {bind }}$ values and structure parameters for four isomers of the complex are presented in the table inset of Fig. 4. In the most stable forms, the $\mathrm{O}_{2}$ subunit is located near the iodine atom with the vector connecting I and the center of mass of $\mathrm{O}_{2}$ pointing almost perpendicular to the $\mathrm{O}-\mathrm{O}$ bond in all of the isomers.

For the $\mathrm{CH}_{3} \mathrm{I}-\mathrm{O}_{2}$ complex $\mathrm{CASSCF}(10,6)$ calculations have been carried out to determine the properties of the CT state. The basis sets used were the same as in the calculations of the structure and binding energy of the ground state of this complex. An active space involved two doubly occupied nonbonding $n p$ orbitals of the I atom as well as two singly occupied antibonding $\pi$ and a pair of doubly occupied bonding $\pi$ orbitals of molecular oxygen. Starting from the isomers that were calculated to be stable, the isomer with the shortest distance between I atom and center of $\mathrm{O}_{2}$ subunit $\left(R_{m}=3.57 \AA\right)$ was chosen, and the energy gap between the ground and CT states of the complex in its equilibrium geometry $\left(\Delta E_{\text {vert }}\right)$ was calculated. The structure parameters of this isomer are marked by bold type in the table inset in Fig. 4. A CT state of $\mathrm{A}^{\prime \prime}$ symmetry was considered in order for it to be accessible by an allowed electric dipole transition from the ground state of the complex (see discussion). The calculated distance in energy between the ground state and this CT state was found to be $\Delta E_{\text {vert }}=5.81 \mathrm{eV}$. Optimization of the CT complex structure has been performed with the $\operatorname{CASSCF}(10,6)$ method and the minimum of energy was found for the CT state with a structure characterized by $\theta$ $=191.8^{\circ}, \varphi=60.7^{\circ}$, and $R_{m}=2.63 \AA$. A single point energy calculation was then carried out for this structure by CASSCF $(10,6)$ MP2 method. The energy of this configuration was found to be higher than the energy of the ground state of the complex by $3.43 \mathrm{eV}$.

\section{DISCUSSION}

We propose that all of the observed $\mathrm{O}$ atom production channels from photodissociation of the $\mathrm{X}-\mathrm{O}_{2}$ complexes originate from two excited states, namely, the $\mathrm{X}^{+}-\mathrm{O}_{2}^{-} \mathrm{CT}$ state and a covalent state with excitation localized in the Herzberg III state of the oxygen molecule, indicated as $\mathrm{X}-\mathrm{O}_{2}\left(A^{\prime}{ }^{3} \Delta_{u}\right)$. A schematic diagram of the states involved is shown in Fig. 5 for the $\mathrm{CH}_{3} \mathrm{I}-\mathrm{O}_{2}$ complex as an example. When building this diagram we assume, like the authors of 


\begin{tabular}{cccc}
\hline$\theta$ & $\varphi$ & $\mathrm{R}_{\mathrm{m}}, \AA$ & $\mathrm{E}_{\text {bind }}, \mathrm{cm}^{-1}$ \\
\hline 0.3 & 90.6 & 5.38 & 98 \\
67.2 & 77.6 & 3.91 & 153 \\
$\mathbf{1 7 9 . 7}$ & $\mathbf{8 9 . 3}$ & $\mathbf{3 . 5 7}$ & $\mathbf{1 4 9}$ \\
285.5 & 102.6 & 3.92 & 144
\end{tabular}

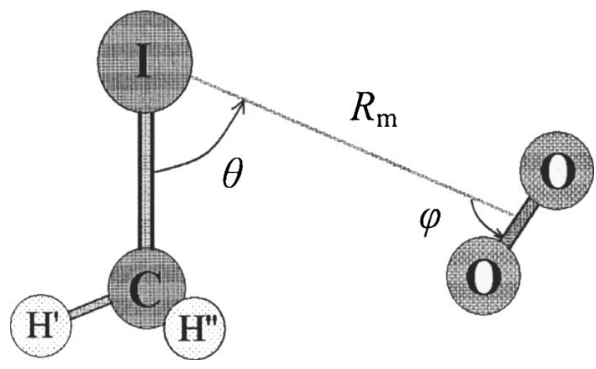

FIG. 4. Calculated structures of the isomers of the $\mathrm{CH}_{3} \mathrm{I}-\mathrm{O}_{2}$ van der Waals complex. Four types of isomers are found to exist, with geometry parameters shown in the table inset. All of these forms have $C_{s}$ symmetry and a degeneracy factor of 3 corresponding to rotation of the $\mathrm{O}_{2}$ subunit around the $C_{3}$ axis of the $\mathrm{CH}_{3} \mathrm{I}$ subunit by $120^{\circ}$. For the form shown, the symmetry plane coincides with the plane of the figure and so one of the $\mathrm{H}$ atoms is screened by the atom $\mathrm{H}^{\prime \prime}$. The vector connecting the I atom and the center of mass of the $\mathrm{O}_{2}$ subunit is almost perpendicular to the $\mathrm{O}-\mathrm{O}$ bond in all of the isomers. In all of these structures the ground state of the $\mathrm{CH}_{3} \mathrm{I}-\mathrm{O}_{2}\left({ }^{3} \Sigma_{g}^{-}\right)$ complex has $A^{\prime \prime}$ symmetry. The numbers marked in bold correspond to the isomer with the shortest $\mathrm{I}-\mathrm{O}_{2}$ distance for which the properties of the charge-transfer electronic excited state have then been calculated (see text)

Refs. 13 and 15, that in the ground and excited states of the complex the rather distant $\mathrm{X}$ partner does not affect the potential energy profile of the $\mathrm{O}_{2}$ subunit along the $R(\mathrm{O}-\mathrm{O})$ coordinate as compared with the free $\mathrm{O}_{2}$ molecule. The potentials of $\mathrm{O}_{2}$ in its ground $\left(X^{3} \Sigma_{g}^{-}\right)$and excited $\left(A^{\prime}{ }^{3} \Delta_{u}\right)$ states are presented as Morse curves. These curves reproduce the literature data for bond energy, geometry, and vibrational energy of $\mathrm{O}_{2}$ in $\left(X^{3} \Sigma_{g}^{-}\right)$(Ref. 30) and $\left(A^{\prime}{ }^{3} \Delta_{u}\right)$ (Ref. 31) states. Two CT states based on $a b$ initio calculations are shown in Fig. 5 for the $\mathrm{CH}_{3} \mathrm{I}-\mathrm{O}_{2}$ complex. The effect of $\mathrm{X}^{+}$ on the profile of potential of $\mathrm{O}_{2}^{-}$in the $\mathrm{X}^{+}-\mathrm{O}_{2}^{-} \mathrm{CT}$ state has been also neglected in our model. Along the $R(\mathrm{O}-\mathrm{O})$ coordinate the CT state potentials are thus those of the free $\mathrm{O}_{2}^{-}$ anion in its ground $\left(X^{2} \Pi_{g}\right)$ and excited $\left(A^{2} \Pi_{u}\right)$ states. The Morse curves presented for these states also reproduce the literature data for bond energy, geometry, and vibrational energy in the upper two states of $\mathrm{O}_{2}^{-}{ }^{30}$ However, the potential of $\mathrm{O}_{2}^{-}$has been shifted up by $5.81 \mathrm{eV}$ as compared with the ground state of complex in its equilibrium geometry. This shift corresponds to the CASSCF calculated energy gap between the ground and lowest CT state of the $\mathrm{CH}_{3} \mathrm{I}-\mathrm{O}_{2}$ complex (see above). The following discussion concerns analysis of the role of the covalent and charge-transfer states in the photodissociation of $\mathrm{X}-\mathrm{O}_{2}$ complexes as well as assignment of the observed $\mathrm{O}$ atom product channels.

\section{Photodissociation via the perturbed $\mathrm{X}-\mathrm{O}_{2}\left(\boldsymbol{A}^{\prime}{ }^{3} \Delta_{u}\right)$ state}

Photodissociation of all four of the studied complexes gives rise to a group of $\mathrm{O}$ atoms $(\mathrm{C} 1)$ with translational energy $E_{t 1}$ close to $E_{t 0}$, the energy released in the one-photon dissociation of free $\mathrm{O}_{2}(\mathrm{C} 0$ in Fig. 1). The well-pronounced recoil anisotropy of channel $\mathrm{C} 1$ (external rings in the images shown Figs. 1(b)-1(e) and the peaks in the corresponding speed distributions (shown Fig. 3) for each of the complexes allow us to conclude that the lifetime of the complex excited in the state giving rise to channel $\mathrm{C} 1$ is shorter than the period of rotation of the complex. The closeness of $E_{t 1}$ to $E_{t 0}$ as well as the prompt (anisotropic) dissociation indicates localization of the excitation on the $\mathrm{O}_{2}$ subunit of the complex. The existence of channel $\mathrm{C} 1$ for the $\mathrm{Xe}-\mathrm{O}_{2}$ complex where the CT state is not accessible with one-photon excitation (see below) supports this interpretation as well. The small difference between $E_{t 1}$ and $E_{t 0}$ (varying from about $110 \mathrm{~cm}^{-1}$ in the case of $\mathrm{Xe}-\mathrm{O}_{2}$ to about $650 \mathrm{~cm}^{-1}$ for the case of

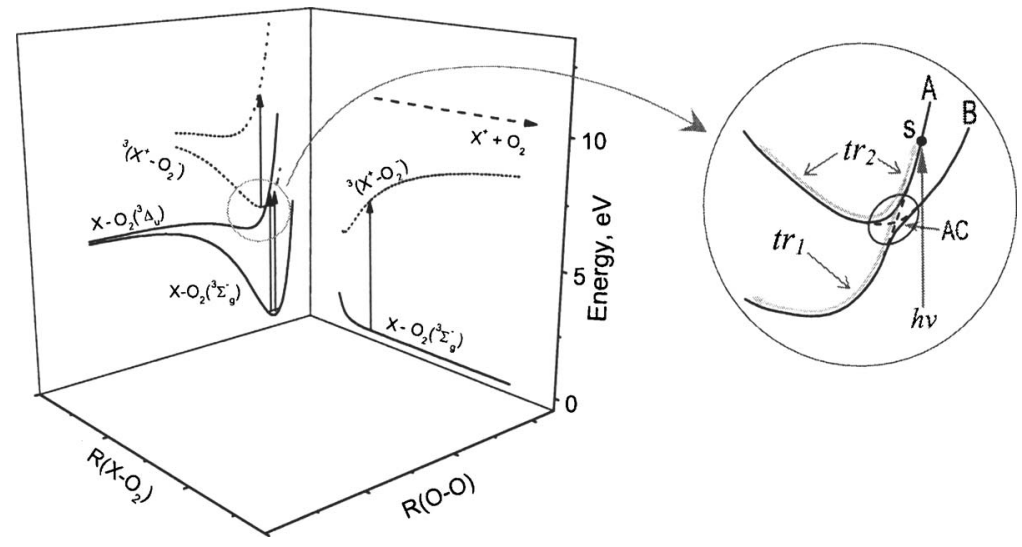

FIG. 5. Potential energy curves for the electronic states of $\mathrm{X}-\mathrm{O}_{2}$ van der Waals complexes. The curves corresponding to the covalent states are shown by solid lines and a dotted line is used for the charge-transfer (CT) states. The potential of the covalent states along the $R(\mathrm{O}-\mathrm{O})$ coordinate is shown for the $\mathrm{O}_{2}$ subunit in the ground $\left(X^{3} \Sigma_{g}^{-}\right)$and excited $\left(A^{\prime 3} \Delta_{u}\right)$ electronic states. The potential for the CT states along the $R(\mathrm{O}-\mathrm{O})$ coordinate is shown for $\mathrm{O}_{2}^{-}$in the ground $\left(X^{2} \Pi_{g}\right)$ and excited $\left(A^{2} \Pi_{u}\right)$ states. The blue line in the plane along the $R\left(\mathrm{X}-\mathrm{O}_{2}\right)$ coordinate corresponds to the ${ }^{3}\left(\mathrm{X}^{+}-\mathrm{O}_{2}^{-}\right) \mathrm{CT}$ state. The energy parameters of the CT states shown in the figure correspond to the calculated values for the $\mathrm{CH}_{3} \mathrm{I}-\mathrm{O}_{2}$ complex (see text). In the plane along the $R(\mathrm{O}-\mathrm{O})$ coordinate the two lower arrows correspond to vertical transitions from the ground state to the CT state and to the covalent state $\mathrm{X}-\mathrm{O}_{2}\left(A^{\prime}{ }^{3} \Delta_{u}\right)$. In the inset the region of diabatic curve crossing (region $A C$ ) is given in more detail. The diabatic states $A$ and $B$ provided by an avoided crossing are shown. A vertical transition to the point $s$ provides excitation to the $\mathrm{X}-\mathrm{O}_{2}\left(A^{\prime 3} \Delta_{u}\right)$ branch of state $A$. The direct dissociation via trajectory $\operatorname{tr}_{1}$ corresponds to channel $\mathrm{C} 1$ (Fig. 1$)$. Dissociation preceded by vibrational motion in the $A$ state $\left(\operatorname{tr}_{2}\right)$ corresponds to channel $\mathrm{C} 2$. 
$\mathrm{C}_{3} \mathrm{H}_{6}-\mathrm{O}_{2}$ ) can be attributed to energy consumed for rupture of the $\mathrm{X}-\mathrm{O}_{2}$ van der Waals bond taking place during photodissociation of the complex by the process

$$
\mathrm{X}-\mathrm{O}_{2}+h \nu \rightarrow \mathrm{X}+\mathrm{O}+\mathrm{O}
$$

as well as for the energy released as translational energy and internal excitation of X. We assume that all of our complexes follow the previously mentioned rule that the Herzberg III state is the predominant contributor in collision-induced enhancement of $\mathrm{O}_{2}$ absorption. We thus consider photodissociation of the complex via the $\mathrm{X}-\mathrm{O}_{2}\left(A^{\prime}{ }^{3} \Delta_{u}\right)$ excited state as being responsible for channel $\mathrm{C} 1$. As we see in Fig. 5, this state is accessible via one-photon absorption at the wavelength used in this study. Channel $\mathrm{C} 1$ is significant in the integral yield of $\mathrm{O}$ atoms from the $\mathrm{X}-\mathrm{O}_{2}$ complex photodissociation for all $\mathrm{X}$ partners studied here (Figs. 1 and 3). This leads us to suggest that the excited state of the complex giving rise to channel $\mathrm{C} 1$ is also (at least partly) responsible for enhanced absorption by the $\mathrm{X}-\mathrm{O}_{2}$ pair.

The observed negative anisotropy of channel $\mathrm{C} 1$ indicates a perpendicular nature of the enhanced transition. This allows us to make a choice between two hypothesis suggested in the literature to explain collision-induced enhancement of oxygen photoabsorption within the Herzberg continuum. In one hypothesis, admixing of the $B^{3} \Sigma_{u}^{-}$ Schumann-Runge state with the $A^{\prime 3} \Delta_{u}$ state was proposed to be responsible for the Herzberg III transition enhancement (the transition $B^{3} \Sigma_{u}^{-} \leftarrow X^{3} \Sigma_{g}^{-}$is electric dipole allowed) for the $\mathrm{X}-\mathrm{O}_{2}$ collisional pair. ${ }^{8,32,33}$ Bernath et al. ${ }^{8}$ with reference to Watson mentioned that collisional mixing of the Herzberg III $\left(A^{\prime}{ }^{3} \Delta_{u}\right)$ state with the higher lying $B^{3} \Sigma_{u}^{-}$state is governed by the quadrupole operator. This admixing is impossible for the two other Herzberg states, $A^{3} \Sigma_{u}^{+}$and $c^{1} \Sigma_{u}^{-8}$. The other hypothesis for enhancement involves the assumption of a critical role of the CT excited state of the collisional complex X- $\mathrm{O}_{2}$, based on the well-pronounced correlation of the enhancement efficiency and ionization potential of the collision partner X. ${ }^{6-8}$ Because the $B^{3} \Sigma_{u}^{-} \leftarrow X^{3} \Sigma_{g}^{-}$transition is parallel, $B^{3} \Sigma_{u}^{-}$admixing which yields enhanced absorption should also be of parallel character relative to $\mathrm{O}-\mathrm{O}$ bond. Parallel $\mathrm{O}$ atom recoil should thus be observed for the Schumann-Runge hypothesis to be valid. We observe a perpendicular recoil anisotropy for $\mathrm{O}$ atoms arising from channel $\mathrm{C} 1$, which implies that the contribution of SR state admixing in enhancement of $\mathrm{O}_{2}$ absorption is not important compared to the second alternative, enhancement due to admixing with the CT state.

The enhancement itself and the predominance of the Herzberg III transition as well as the observed anisotropy of enhanced photodissociation can be understood if enhancement is governed by admixing of the ${ }^{3}\left(X^{+}-\mathrm{O}_{2}^{-}\right)$chargetransfer state of the complex. To demonstrate this we should first consider the model of Mulliken for charge-transfer transitions in loose (weakly bound) molecular complexes. ${ }^{34} \mathrm{Ac}-$ cording to Mulliken, the wave functions of the ground $\left(\Psi_{N}\right)$ and excited CT state $\left(\Psi_{E}\right)$ of complex $A-B$ can be considered to be combinations of the wave functions of the purely "no-bond" (with respect to covalent bonding) wave function $\varphi_{0}=\varphi(A-B)$ and the dative wave function $\varphi_{1}=\varphi\left(A^{-}-B^{+}\right)$ corresponding to the transfer of an electron from $B$ to $A$. These combinations are $\Psi_{N}=a \varphi_{0}+b \varphi_{1}$ and $\Psi_{E}=a^{*} \varphi_{1}-b^{*} \varphi_{0}$. The symmetry of the no-bond and dative states should be the same (which is necessary for $b$ to be nonzero). According to Mulliken, the transition dipole moment $\left(\boldsymbol{\mu}_{E N}\right)$ for the $E$ $\leftarrow N$ transition can be written in the equation

$$
\boldsymbol{\mu}_{E N}=a^{*} b\left(\boldsymbol{\mu}_{1}-\boldsymbol{\mu}_{0}\right)+\left(a a^{*}-b b^{*}\right)\left(\boldsymbol{\mu}_{01}-S \cdot \boldsymbol{\mu}_{0}\right),
$$

where $\boldsymbol{\mu}_{1}$ and $\boldsymbol{\mu}_{0}$ are the permanent dipole moments of the pure dative $\left(A^{-}-B^{+}\right)$and no-bond $(A-B)$ states, $\boldsymbol{\mu}_{01}$ is the transition dipole moment for the transition between these pure states $\left(A^{-}-B^{+}\right) \leftarrow(A-B)$. According to estimations by Mulliken ${ }^{34}$ the first term of the right side of Eq. (2) should dominate for the case of loose complexes $\left(a^{2} \gg b^{2}\right)$. Taking into account that the dipole moment of the dative state $\boldsymbol{\mu}_{1}$ is much larger than that for the no-bond state, the upper equation can be rewritten as $\boldsymbol{\mu}_{E N} \approx a^{*} b \boldsymbol{\mu}_{1}$. The transition dipole moment for CT excitation should thus be approximately directed along the permanent dipole moment of dative state. To provide the perpendicular nature of the transition to the excited mixed state, the permanent dipole moment $\boldsymbol{\mu}_{1}$ of the ${ }^{3}\left(\mathrm{X}^{+}-\mathrm{O}_{2}^{-}\right)$CT state should be directed perpendicular to the $\mathrm{O}-\mathrm{O}$ bond. Taking into account this conclusion, we consider our complexes under study. In the most stable forms of all these complexes the electron donor is located near the center of the $\mathrm{O}-\mathrm{O}$ bond. According to the calculated structure of the most stable isomers of the $\mathrm{CH}_{3} \mathrm{I}-\mathrm{O}_{2}$ complex (Fig. 4) the $\mathrm{O}-\mathrm{O}$ bond is approximately perpendicular to the chargetransfer direction from the $\mathrm{I}$ atom to the center of the $\mathrm{O}_{2}$ molecule. According to $a b$ initio calculations by DeBoer et al. ${ }^{14}$ for the complex of the simplest alkene $\mathrm{C}_{2} \mathrm{H}_{4}$ with oxygen, the stable form of the complex $\mathrm{C}_{3} \mathrm{H}_{6}-\mathrm{O}_{2}$ should correspond to the bisected structure [Fig. 4(a) in Ref. 14] where the $\mathrm{O}-\mathrm{O}$ bond is directed perpendicular to the plane of the ethylenic $\left(\mathrm{H}_{2} \mathrm{C}=\mathrm{CH}-\right)$ fragment with the center of the $\mathrm{O}_{2}$ subunit located by the center of the $\pi$ bond of $\mathrm{C}_{3} \mathrm{H}_{6}$. In the CT state of this complex, the permanent dipole moment $\boldsymbol{\mu}_{1}$ is thus directed perpendicular to the $\mathrm{O}-\mathrm{O}$ bond. For $\mathrm{C}_{6} \mathrm{H}_{12}-\mathrm{O}_{2}$, according to calculations by Parsons and Chandler ${ }^{15}$ the lower-energy isomer corresponds to the socalled resting structure (Fig. 1(b) of Ref. 15) where $\mathrm{O}_{2}$ lies above the $\mathrm{C}_{6} \mathrm{H}_{12}$ ring with the direction between the centers of $\mathrm{C}_{6} \mathrm{H}_{12}$ and $\mathrm{O}_{2}$ parts being perpendicular to the $\mathrm{O}-\mathrm{O}$ bond. In this case, the direction of $\boldsymbol{\mu}_{1}$ in the CT state should thus again be perpendicular to the $\mathrm{O}-\mathrm{O}$ bond. The potential energy surface of the $\mathrm{Xe}-\mathrm{O}_{2}$ pair was studied by Aquilanti et al. in scattering experiments. ${ }^{35}$ According to their results, the global minimum corresponds to a triangular $\mathrm{T}$ shape with Xe being located across from the center of the $\mathrm{O}_{2}$ subunit. Prompt photodissociation of all of these complexes in their most stable forms should thus provide a perpendicular recoil. We can conclude that the experimentally observed perpendicular character of the excited state giving rise to the $\mathrm{C} 1$ channel is consistent with admixing of the CT state as the source of enhancement of the Herzberg absorption in $\mathrm{X}-\mathrm{O}_{2}$ complexes.

The experimentally established predominance of the Herzberg III transition in the enhanced absorption of $\mathrm{O}_{2}$ can be also explained within this mechanism of admixing of the 
CT state with the excited state of a complex where $\mathrm{O}_{2}$ is excited to a Herzberg state. First of all, we can neglect a transition where the $\mathrm{O}_{2}$ subunit of the complex is excited in the Herzberg II $\left(c^{1} \Sigma_{u}^{-}\right)$state due to the spin forbidden nature. In the analysis of possible contributions of Herzberg I and III transitions in $\mathrm{O}_{2}$ subunit, symmetry arguments are useful. In the simplest case of an $\mathrm{X}-\mathrm{O}_{2}$ complex, the electron donor $\mathrm{X}$ can be considered as a point mass that coincides with an atom donating an electron for transfer. This would be the xenon atom in the case of $\mathrm{Xe}-\mathrm{O}_{2}$ and an iodine atom in the case of the $\mathrm{CH}_{3} \mathrm{I}-\mathrm{O}_{2}$ complex, or the center of the electron donor portion of the $\mathrm{X}$ fragment (the center of $\pi$ bond in $\mathrm{C}_{3} \mathrm{H}_{6}-\mathrm{O}_{2}$ complex or the center of the $\mathrm{C}_{6} \mathrm{H}_{12}$ ring in $\mathrm{C}_{6} \mathrm{H}_{12}-\mathrm{O}_{2}$ ). In this case, the $\mathrm{X}-\mathrm{O}_{2}$ complex can be considered as composed of three point masses with $C_{s}$ symmetry in the general case. The ground state of the complex $\mathrm{X}-\mathrm{O}_{2}\left(X^{3} \Sigma_{g}^{-}\right)$corresponds to the irreducible representation $A^{\prime \prime}$ of the group $C_{s}$. For a transition to the CT state to be allowed, the symmetry of the ground and CT states should coincide, ${ }^{34}$ i.e., the CT state should be of $A^{\prime \prime}$ symmetry. In turn, mixing of the $A^{\prime \prime} \mathrm{CT}$ state can take place only with an $A^{\prime \prime}$ excited state of the complex. In the $C_{s}$ group, $\mathrm{X}-\mathrm{O}_{2}\left(A^{3} \Sigma_{u}^{+}\right)$(where oxygen in the Herzberg I state) is of $A^{\prime}$ type, which does not allow this mixing. The $\mathrm{X}-\mathrm{O}_{2}\left(A^{\prime}{ }^{3} \Delta_{u}\right)$ state, however, can split in $C_{s}$ symmetry into an $A^{\prime}$ and $A^{\prime \prime}$ pair of states and the latter one can mix with the CT state. Collisional enhancement of $\mathrm{O}_{2}$ absorption through admixture of the CT state of the $\mathrm{X}-\mathrm{O}_{2}$ complex can thus take place only for the Herzberg III transition of $\mathrm{O}_{2}$. Considered along the $\mathrm{O}-\mathrm{O}$ coordinate, the potential curve of the $\mathrm{X}-\mathrm{O}_{2}\left(A^{\prime}{ }^{3} \Delta_{u}\right)$ state should be roughly independent of the closed shell $\mathrm{X}$ partner. This state should thus be accessible by absorption at the wavelength used for any $\mathrm{X}-\mathrm{O}_{2}$ pair.

\section{Photodissociation via direct excitation to the charge-transfer ${ }^{3}\left(\mathrm{X}^{+}-\mathrm{O}_{2}^{-}\right)$state}

Direct absorption into the charge-transfer state of the complex is revealed by the appearance of the oxygen molecular anion $\mathrm{O}_{2}^{-}$(superoxide anion) which is observed only when the $\mathrm{CH}_{3} \mathrm{I}-\mathrm{O}_{2}$ and $\mathrm{C}_{3} \mathrm{H}_{6}-\mathrm{O}_{2}$ complexes are excited. The formation of $\mathrm{O}_{2}^{-}$anions is indicated by formation of $\mathrm{O}$ atoms in the characteristic channel $\mathrm{C} 5$. The energy and recoil anisotropy of these $\mathrm{O}$ atoms corresponds to the photodissociation of the superoxide anion via the process

$$
\mathrm{O}_{2}^{-} \stackrel{h \nu}{\longrightarrow} \mathrm{O}+\mathrm{O}^{-}, \quad \mathrm{D}_{0}\left(\mathrm{O}_{2}^{-}\right)=4.104 \mathrm{eV} \text { (Ref. 30). }
$$

The measured kinetic energy of the $\mathrm{O}\left({ }^{3} P_{2}\right)$ atoms arising in channel C5 is equal to $E_{t 5}=0.69 \mathrm{eV}\left(\mathrm{CH}_{3} \mathrm{I}-\mathrm{O}_{2}\right)$ and $0.68 \mathrm{eV}$ $\left(\mathrm{C}_{3} \mathrm{H}_{6}-\mathrm{O}_{2}\right)$ and within the experimental scatter (about $0.04 \mathrm{eV}$ ) coincides with the value expected for the processes (3) $E_{t}=\left(h \nu-\mathrm{D}_{0}\left(\mathrm{O}_{2}^{-}\right)\right) / 2=0.695 \mathrm{eV}$. Lavrich et al. ${ }^{36}$ and Dinu et $a l{ }^{37}$ studied UV photodissociation of $\mathrm{O}_{2}^{-}$in wavelength regions close to ours and found that process (3) takes place by a $A^{2} \Pi_{u} \leftarrow X^{2} \Pi_{u}$ parallel transition. This is in agreement with the parallel character of channel C5 in our experiments (Fig. 2). A significant $\mathrm{O}\left({ }^{3} P_{0}\right)$ yield was also found in Ref. 37 , consistent with the relative signal strengths of channel C5 observed in Fig. 2(a) for $\mathrm{O}\left({ }^{3} P_{2}\right)$ versus Fig. 2(b) for
$\mathrm{O}\left({ }^{3} P_{0}\right)$ detection. The formation of $\mathrm{O}_{2}^{-}$indicates the chargetransfer character of its precursor $\mathrm{X}^{+}-\mathrm{O}_{2}^{-}$excited by onephoton excitation of the $\mathrm{X}-\mathrm{O}_{2}\left(\mathrm{X}=\mathrm{CH}_{3} \mathrm{I}, \mathrm{C}_{3} \mathrm{H}_{6}\right)$ complexes. We suppose that photodissociation of this charge-transfer state gives rise to the superoxide anion via the process

$$
\mathrm{X}^{+}-\mathrm{O}_{2}^{-} \stackrel{h \nu}{\longrightarrow} \mathrm{X}^{+}+\mathrm{O}_{2}^{-} \text {. }
$$

The CASSCF calculations described above confirm that one quantum of $226 \mathrm{~nm}$ radiation is sufficient for direct vertical excitation into the $\mathrm{CT}$ state of the $\mathrm{CH}_{3} \mathrm{I}-\mathrm{O}_{2}$ complex. The calculated energy gap between the ground and chargetransfer states in the equilibrium geometry of the $\mathrm{CH}_{3} \mathrm{I}-\mathrm{O}_{2}$ complex is $\Delta E_{\mathrm{vert}}=5.81 \mathrm{eV}$ while the photon energy used is $h \nu=5.494 \mathrm{eV}$. Our CASSCF calculations, however, have been carried out without taking spin-orbit coupling in $\mathrm{CH}_{3} \mathrm{I}^{+}$ into account. This coupling provides a splitting between the spin-orbit substates ${ }^{2} E_{3 / 2}$ and ${ }^{2} E_{1 / 2}$ at the level of about $0.6 \mathrm{eV} .^{38}$ The value of $\Delta E_{\mathrm{vert}}$ calculated when spin-orbit coupling was omitted should thus be corrected by subtracting an extra $\sim 0.2 \mathrm{eV}$. The resulting value $\Delta E_{\mathrm{vert}} \approx 5.6 \mathrm{eV}$ is almost equal to the quantum of radiation used and so the excitation wavelength should be close to the CT absorption maximum. Direct excitation to the CT state is thus possible, as shown in Fig. 5. DeBoer et al. found in a similar calculation that the CT state of the $\mathrm{C}_{3} \mathrm{H}_{6}-\mathrm{O}_{2}$ complex is also accessible at this wavelength. ${ }^{14}$

Channel $\mathrm{C} 5$ was not observed in our experiments for the $\mathrm{Xe}-\mathrm{O}_{2}$ and $\mathrm{C}_{6} \mathrm{H}_{12}-\mathrm{O}_{2}$ complexes. This can be understood at least for the $\mathrm{Xe}-\mathrm{O}_{2}$ complex if we consider the factors affecting the position of CT absorption in $\mathrm{X}-\mathrm{O}_{2}$ complexes. The lowest CT state energy in the equilibrium geometry of the $\mathrm{X}-\mathrm{O}_{2}$ complex depends on the nature of $\mathrm{X}$ and particularly on its ionization potential $\mathrm{IP}_{\mathrm{X}}$. At the quite long distance $R$ between the subunits characteristic for the loose $\mathrm{X}-\mathrm{O}_{2}$ complex the vertical gap $\Delta E_{\text {vert }}$ between ground and CT states of the complex can be estimated following Mulliken $^{34}$ via the process

$$
\Delta E_{\mathrm{vert}} \approx \mathrm{IP}_{\mathrm{vert}}(\mathrm{X})-\mathrm{EA}_{\mathrm{vert}}\left(\mathrm{O}_{2}\right)-\frac{e^{2}}{R} \approx \mathrm{IP}_{\mathrm{vert}}(\mathrm{X})-\frac{e^{2}}{R},
$$

where $\operatorname{IP}_{\text {vert }}(\mathrm{X})$ is the vertical ionization potential of $\mathrm{X}$, $\mathrm{EA}_{\text {vert }}\left(\mathrm{O}_{2}\right)$ is the vertical electron affinity of $\mathrm{O}_{2}$, which is close to zero (Ref. 30) and $\left(-e^{2} / R\right)$ is the Coulomb interaction of $\mathrm{X}^{+}$and $\mathrm{O}_{2}^{-}$in the CT state. The IP of the $\mathrm{X}$ partners increases in the series $9.54 \mathrm{eV}\left(\mathrm{CH}_{3} \mathrm{I}\right)<9.73 \mathrm{eV}\left(\mathrm{C}_{3} \mathrm{H}_{6}\right)$ $<9.86 \mathrm{eV}\left(\mathrm{C}_{6} \mathrm{H}_{12}\right)<12.13 \mathrm{eV}(\mathrm{Xe}) .{ }^{39}$ For $\mathrm{X}=\mathrm{Xe}$ the CT state is inaccessible by a vertical transition because $h \nu<\Delta E_{\text {vert }}$ $\approx 8.4 \mathrm{eV}$ (estimated with $R=3.87 \AA$ as experimentally determined for the T-shaped complex ${ }^{35}$ ). In the case of cyclohexane, the $\mathrm{IP}_{\mathrm{X}}$ value is not much larger than that for $\mathrm{CH}_{3} \mathrm{I}$ and $\mathrm{C}_{3} \mathrm{H}_{6}$ and we could expect a contribution of CT transition. At the same time, we can expect that other factors such as the lifetime of the complex in the CT state could affect the yield of $\mathrm{O}_{2}^{-}$photodissociation, process (3), which is responsible for channel C5. For example, the increase in the decay rate of the CT state via any channel (like channel C3 discussed below) would reduce the yield of channel C5. We expect that 
time-resolved studies could be useful in elucidation of this issue.

After the CT state is excited, a second laser photon can be absorbed, as shown in Fig. 5. To a first approximation, the gap between the CT ground and excited states involving the $\mathrm{O}_{2}^{-}$subunit in the states $X^{2} \Pi_{u}$ and $A^{2} \Pi$, respectively, does not depend on the $\mathrm{X}$ partner. At the wavelength used, $\mathrm{X}^{+}-\mathrm{O}_{2}^{-}$ photodissociation, process (4), should thus take place for the $\mathrm{CT}$ complex with any $\mathrm{X}$ partner, as shown in Fig. 5 for $\mathrm{CH}_{3} \mathrm{I}-\mathrm{O}_{2}$. The allowed transition $A^{2} \Pi_{u} \leftarrow X^{2} \Pi_{u}$ in the $\mathrm{O}_{2}^{-}$ subunit provides a rather broad and intense absorption spectrum. This spectrum for the free superoxide anion $\mathrm{O}_{2}^{-}$dissolved in water and ethanol solutions was measured by Bielski and Gebicki ${ }^{40}$ and was found to have a maximum at about $240 \mathrm{~nm}$ with a cross section of about $10^{-17} \mathrm{~cm}^{2}$ and a full width at half maximum of about 60-70 $\mathrm{nm}$. We suppose that similar absorption takes place in the CT state of ${ }^{3}\left(\mathrm{X}^{+}-\mathrm{O}_{2}^{-}\right)$complex after absorption of laser radiation and giving rise to the photodissociation process (4).

The $\mathrm{O}_{2}^{-}$superoxide anion arising in process (4) can be assigned as a precursor of the $\mathrm{O}\left({ }^{3} P_{J}\right)$ atoms observed in the weak parallel channel $\mathrm{C} 4$, seen for photodissociation of $\mathrm{CH}_{3} \mathrm{I}-\mathrm{O}_{2}$ [Fig. 1(e)]. Channel $\mathrm{C} 4$ corresponds to dissociation of the excited singlet state $\mathrm{O}_{2}\left(b^{1} \Sigma_{g}^{+}\right)$of molecular oxygen by the process

$\mathrm{O}_{2}\left(b^{1} \Sigma_{g}^{+}\right) \stackrel{h \nu}{\longrightarrow} \mathrm{O}\left({ }^{3} P_{J}\right)+\mathrm{O}\left({ }^{1} D\right), \quad \Delta E(J=2)=0.037 \mathrm{eV}$,

where $\Delta E(J=2)$ is the total kinetic energy of the photofragments formed in $\mathrm{O}\left({ }^{3} P_{J}\right), J=2$. In turn, $\mathrm{O}_{2}\left(b^{1} \Sigma_{g}^{+}\right)$arises from the photodetachment of $\mathrm{O}_{2}^{-}$by the process

$$
\mathrm{O}_{2}^{-} \stackrel{h \nu}{\longrightarrow} \mathrm{O}_{2}\left(b^{1} \Sigma_{g}^{+}, \ldots\right)+\bar{e} .
$$

$\mathrm{O}_{2}^{-}$photodissociation, process (3), is only a minor channel in the photodecay of $\mathrm{O}_{2}^{-}$, which is mainly governed by electron

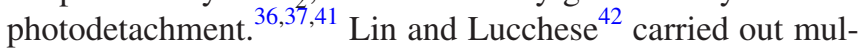
tichannel scattering calculations of this photodetachment. According to their results, photodetachment, process (7), yields neutral $\mathrm{O}_{2}$ in all electronic states accessible with one quantum, and particularly the $\mathrm{O}_{2}\left(b^{1} \Sigma_{g}^{+}\right)$state. Eppink et al. ${ }^{43}$ have characterized process (6) experimentally. A parallel transition with a strong predominance for $\mathrm{O}\left({ }^{3} P_{2}\right)$ production was observed in Ref. 43, with an $\mathrm{O}\left({ }^{3} P_{2}\right)$ kinetic energy of about $150 \mathrm{~cm}^{-1}(0.019 \mathrm{eV})$. For channel $\mathrm{C} 4$ we also observe a parallel character, low $\mathrm{O}$ atom kinetic energy $(0.01-0.02 \mathrm{eV})$ and the predominance of $\mathrm{O}\left({ }^{3} P_{2}\right)$ product. The reduction in the yield of channel $\mathrm{C} 4$ for the case of $\mathrm{O}\left({ }^{3} P_{0}\right)$ production from fragmentation of the $\mathrm{CH}_{3} \mathrm{I}-\mathrm{O}_{2}$ complex is illustrated in Fig. 2(b). These are strong indications that photodissociation of singlet $\mathrm{O}_{2}$ in the $b$ state, process (6), is responsible for channel $\mathrm{C} 4$.

The low kinetic energy isotropic channel C3 (Fig. 1) can also be attributed to direct absorption into the CT state. The isotropic character of $\mathrm{C} 3$ can be explained by the fact that the CT state is bound (see Fig. 5), so the lifetime of the complex relative to spontaneous decay

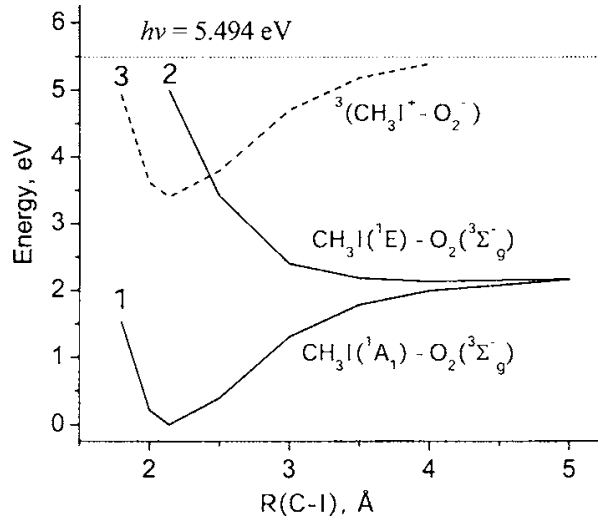

FIG. 6. Cross section of the potential energy surface of the $\mathrm{CH}_{3} \mathrm{I}-\mathrm{O}_{2}$ complex along the $\mathrm{C}-\mathrm{I}$ coordinate. Solid line 1 corresponds to the ground state of the complex and solid line 2 corresponds to the excited state of complex where the methyl iodide is in a repulsive state. These profiles were built with the use of energy values calculated by Tadjeddine et al. in the $\Lambda$ representation for the states ${ }^{1} A_{1}$ and ${ }^{1} E$ of $\mathrm{CH}_{3} \mathrm{I}$ (Ref. 45). The dashed line 3 corresponds to the ${ }^{3}\left(\mathrm{CH}_{3} \mathrm{I}^{+}-\mathrm{O}_{2}^{-}\right)$charge-transfer state. This potential was assumed to be similar to the potential of the $\mathrm{CH}_{3} \mathrm{I}^{+}$ion which in turn was taken to be similar to the potential of the ground state of $\mathrm{CH}_{3} \mathrm{I}$ because of the nonbonding character of ionization in methyl iodide (Refs. 40 and 46). The gap between the minima of the CT state and the ground state of the complex corresponds to $3.43 \mathrm{eV}$, as calculated in this work. The dotted line indicates the photon energy.

$$
\mathrm{X}^{+}-\mathrm{O}_{2}^{-} \rightarrow\left(\mathrm{X}-\mathrm{O}_{2}\right)^{*} \rightarrow \mathrm{X}+\mathrm{O}+\mathrm{O}
$$

can be much longer than a rotational period. We observe channel $\mathrm{C} 3$ for the complexes $\mathrm{C}_{6} \mathrm{H}_{12}-\mathrm{O}_{2}$ and $\mathrm{C}_{3} \mathrm{H}_{6}-\mathrm{O}_{2}$ [Figs. 1(c) and 1(d)], but not for $\mathrm{CH}_{3} \mathrm{I}-\mathrm{O}_{2}$ [Fig. 1(e)]. The absence of this channel in the case of $\mathrm{CH}_{3} \mathrm{I}-\mathrm{O}_{2}$ can be explained by competitive dissociation via the $\mathrm{C}-\mathrm{I}$ bond of the $\mathrm{CH}_{3} \mathrm{I}$ subunit. A mechanism for dissociation of the $\mathrm{CH}_{3} \mathrm{I}-\mathrm{O}_{2}$ complex via $\mathrm{C}-\mathrm{I}$ bond breaking is illustrated in Fig. 6. This dissociation is promoted by a crossing of the CT state with a state repulsive in the $\mathrm{C}-\mathrm{I}$ coordinate. A potential energy curve for this state has been constructed for free $\mathrm{CH}_{3} \mathrm{I}$, where the effect of the nearby $\mathrm{O}_{2}$ molecule on the potential of electronically excited $\mathrm{CH}_{3} \mathrm{I}$ in the ${ }^{1} E$ state is neglected. The $\mathrm{CH}_{3} \mathrm{I}\left({ }^{1} E\right)-\mathrm{O}_{2}\left({ }^{3} \Sigma_{g}^{-}\right)$state splits under $C_{s}$ geometry, giving rise to $A^{\prime}$ and $A^{\prime \prime}$ states, where the latter has the same symmetry as the excited CT state. These states can thus effectively interact in the region of their crossing, causing the dissociation of the complex via $\mathrm{C}-\mathrm{I}$ bond.

Channel $\mathrm{C} 2$, observed for the case of $\mathrm{CH}_{3} \mathrm{I}-\mathrm{O}_{2}$, shows the same angular anisotropy of $\mathrm{O}$ atom recoil directions as that of channel $\mathrm{C} 1$, but with a lower kinetic energy. This suggests that channel $\mathrm{C} 2$ also goes via the perturbed $\mathrm{X}-\mathrm{O}_{2}\left(A^{\prime}{ }^{3} \Delta_{u}\right)$ state, but where a small amount of energy transfer takes place before dissociation. Interestingly, the energy difference $E_{t 1}-E_{t 2}$ between channels $\mathrm{C} 1$ and $\mathrm{C} 2$, $530 \mathrm{~cm}^{-1}$, is equivalent to one quantum of $\mathrm{C}-\mathrm{I}$ stretch in $\mathrm{CH}_{3}$ I. This weak but clear channel $\mathrm{C} 2$ can be interpreted in the following overall mechanism for cluster-enhanced absorption and dissociation.

This $A^{\prime}{ }^{3} \Delta_{u}$ covalent state, together with the ${ }^{3}\left(\mathrm{X}^{+}-\mathrm{O}_{2}^{-}\right)$ CT state, give rise to the adiabatic channels $\mathrm{A}$ and $\mathrm{B}$ shown in the inset in Fig. 5. The adiabatic state $\mathrm{A}$ is formed by the right branch of the curve for the $\mathrm{X}-\mathrm{O}_{2}\left(A^{\prime}{ }^{3} \Delta_{u}\right)$ state and the 

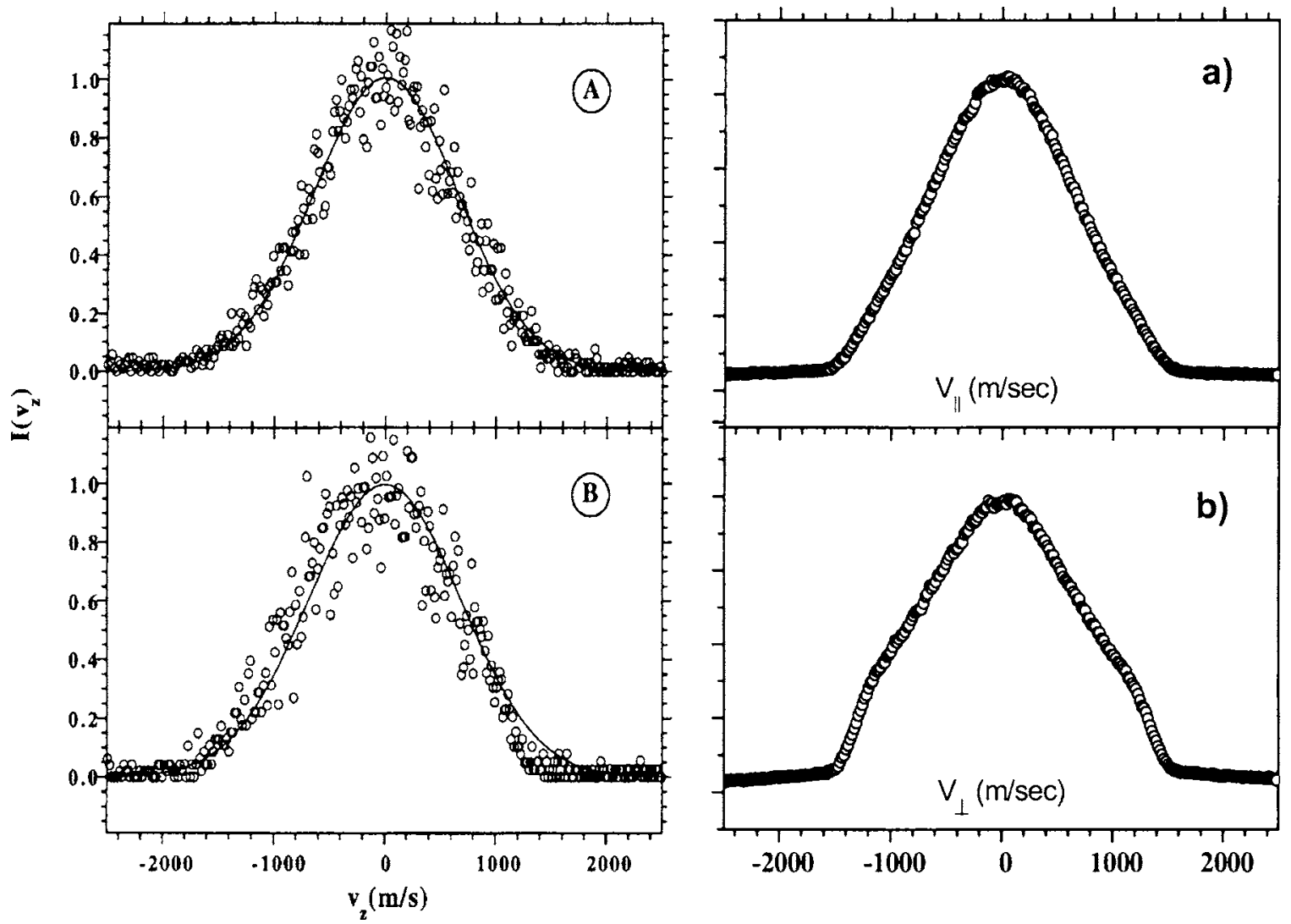

FIG. 7. Velocity distribution profiles (reproduced from Fig. 2 of Ref. 16 with permission) obtained by DeBoer et al. for $\mathrm{O}\left({ }^{3} P_{2}\right)$ atoms arising from the photodissociation of $\mathrm{C}_{3} \mathrm{H}_{6}-\mathrm{O}_{2}$ clusters at $225.656 \mathrm{~nm}$. (A) Distribution of the velocity projection on the axis parallel to the polarization direction of photolysis light; (B) the same for the axis perpendicular to the polarization direction. (a) Projection of the crushed velocity map image obtained in our experiment on the photodissociation of clusters $\mathrm{C}_{3} \mathrm{H}_{6}-\mathrm{O}_{2}$ at the same wavelength $225.656 \mathrm{~nm}$ [Fig. 1(d)] onto the vertical axis (parallel to the laser polarization direction); (b) projection of the same image on the horizontal axis (perpendicular to the laser polarization direction).

left branch of the CT state. A vertical transition to the point $s$ marks excitation to the $\mathrm{X}-\mathrm{O}_{2}\left(A^{\prime}{ }^{3} \Delta_{u}\right)$ branch of state $A$. Direct dissociation via trajectory $\operatorname{tr}_{1}$ gives rise to channel $\mathrm{C} 1$. Vibrational motion in state $A$ (trajectory $\operatorname{tr}_{2}$ ) preceding dissociation gives rise to channel $\mathrm{C} 2$. We assume that this vibrational motion is followed by redistribution of energy from the $\mathrm{O}-\mathrm{O}$ coordinate to the vibrational reservoir of the complex in state $A$, and so the predissociation gives rise to $\mathrm{O}$ atoms with a lower kinetic energy. The retained recoil anisotropy in channel $\mathrm{C} 2$ shows that corresponding $\mathrm{O}$ atoms appear on a time scale shorter than the period of rotation of the complex.

Note that coupling from electronic to vibrational energy (into channels $\mathrm{C} 2$ and $\mathrm{C} 3$ ) can also be described in terms of the back electron transfer model of Cheng et al. ${ }^{44}$ in which for our case the charge-transfer step forming $\mathrm{O}_{2}^{-}-\mathrm{X}^{+}$is followed by back electron transfer to make $\mathrm{O}_{2}^{*}-\mathrm{X}$, where the $\mathrm{O}_{2}$ species is electronically excited in one of the Herzberg upper states. The newly formed neutral $\mathrm{O}_{2}^{*}-\mathrm{X}$ covalent electronic state has different internuclear distances than the original species, resulting in rapid vibrational excitation.

The relative contribution of photodissociation via the charge-transfer and perturbed covalent states can be roughly estimated for the complexes $\mathrm{CH}_{3} \mathrm{I}-\mathrm{O}_{2}$ and $\mathrm{C}_{3} \mathrm{H}_{6}-\mathrm{O}_{2}$. The contribution of $\mathrm{C} 5$ channel in the yield of $\mathrm{O}$ atoms was measured to be about $3 \%$ and $2 \%$ for these two complexes, respectively. However, $\mathrm{O}_{2}^{-}$photodissociation, process (3), as mentioned above, is minor compared with the photodetachment. According to the results of measurements near $266 \mathrm{~nm}$, the contribution of process (3) was found to be only $3 \%$ (Ref. 36) or $10 \% .{ }^{37}$ According to Lavrich et al. ${ }^{36}$ this strong predominance of electron photodetachment takes place also around $226 \mathrm{~nm}$, the wavelength region used in the current paper. Direct absorption to the CT state is thus a major factor in the enhanced absorption by the $\mathrm{CH}_{3} \mathrm{I}-\mathrm{O}_{2}$ and $\mathrm{C}_{3} \mathrm{H}_{6}-\mathrm{O}_{2}$ complexes, but its contribution to the $\mathrm{O}$ atom yield via channel $\mathrm{C} 5$ is low, $3 \%$ and $2 \%$, respectively.

\section{CONCLUSIONS}

Oxygen atom formation following the UV photoexcitation of the $\mathrm{X}-\mathrm{O}_{2}$ van der Waals complexes with $\mathrm{X}=\mathrm{CH}_{3} \mathrm{I}$, $\mathrm{C}_{3} \mathrm{H}_{6}, \mathrm{C}_{6} \mathrm{H}_{12}$, and $\mathrm{Xe}$ is dramatically different from photodissociation of free $\mathrm{O}_{2}$ molecules. The photodissociation yield is much higher and for the four different complexes studied, at least five different channels giving rise to $\mathrm{O}$ atoms with specific kinetic energy distributions and angular anisotropy are observed. Two main one-photon excitation pathways are proposed. The first is direct excitation to the $\mathrm{X}-\mathrm{O}_{2}\left(A^{\prime}{ }^{3} \Delta_{u}\right)$ covalent state where excitation is localized as the Herzberg III state of the perturbed $\mathrm{O}_{2}$ subunit. This mechanism is universal and should take place for any $\mathrm{X}$. The Herzberg III transition, forbidden in the free $\mathrm{O}_{2}$ molecule, dramatically increases in intensity in the $\mathrm{X}-\mathrm{O}_{2}$ complex due 
to admixing of the wave function of the charge transfer (CT) state ${ }^{3}\left(\mathrm{X}^{+}-\mathrm{O}_{2}^{-}\right)$. This mechanism is responsible for the universal collision-induced enhancement of the $\mathrm{O}_{2}$ photoabsorption within the Herzberg band, taking place in the gas phase or condensed medium. This admixing also explains the predominance of the Herzberg III transition in the enhanced absorption observed experimentally by many authors for $\mathrm{O}_{2}$ in the gas and solid phases. An alternative hypothesis of enhanced absorption due to environment assisted admixing of the Schumann-Runge band is not supported by the results obtained.

Another excitation pathway takes place for $\mathrm{X}-\mathrm{O}_{2}$ complexes $\left(\mathrm{X}=\mathrm{CH}_{3} \mathrm{I}, \mathrm{C}_{3} \mathrm{H}_{6}\right.$, and probably $\mathrm{C}_{6} \mathrm{H}_{12}$ in our experiments) when the $\mathrm{CT}$ state is accessible. One-photon excitation generates the ${ }^{3}\left(\mathrm{X}^{+}-\mathrm{O}_{2}^{-}\right)$CT state which can dissociate on a long time scale, giving rise to $\mathrm{O}$ atoms with an isotropic angular distribution $\left(\mathrm{X}=\mathrm{C}_{3} \mathrm{H}_{6}\right.$ and $\left.\mathrm{C}_{6} \mathrm{H}_{12}\right)$. The $\mathrm{CT}$ state has a very intense $\mathrm{UV}$-absorption band, characteristic for the $\mathrm{O}_{2}^{-}$ subunit. Absorption of another photon from the same laser pulse initiates dissociation of the CT state and formation of $\mathrm{O}_{2}^{-}$, the superoxide anion. The free $\mathrm{O}_{2}^{-}$then absorbs another photon and gives rise to $\mathrm{O}$ atoms (together with $\mathrm{O}^{-}$) with an experimentally observed parallel image pattern and high kinetic energy $\left(E_{t}=0.69 \pm 0.04\right.$ and $0.68 \mathrm{eV}$ for $\mathrm{CH}_{3} \mathrm{I}-\mathrm{O}_{2}$ and for $\mathrm{C}_{3} \mathrm{H}_{6}-\mathrm{O}_{2}$, respectively). A parallel image pattern of low kinetic energy $\mathrm{O}$ atoms arising in the photodissociation of singlet molecular oxygen $\mathrm{O}_{2}\left(b^{1} \Sigma_{g}^{+}\right)$has been also detected $\left(\mathrm{X}=\mathrm{CH}_{3} \mathrm{I}\right)$. Singlet oxygen can appear in the electron photodetachment of the superoxide anion or directly in the photodissociation of the $\mathrm{X}-\mathrm{O}_{2}$ complex.

\section{ACKNOWLEDGMENTS}

The authors gratefully acknowledge the financial support of this work by the Dutch National Science foundation NWO (Grant No. 047.009.011) as well as support by the Russian Foundation of Basic Research (Grant No. 06-03-32542) and by Siberian Branch of Russian Academy of Sciences (interdisciplinary Grant No. 62). The computing time on the SGI Origin 3800 system of SARA Computing and Networking Services in Amsterdam was provided by the Dutch National Computer Facility NCF.

\section{APPENDIX: THE COMPARISON OF OUR DATA WITH THE DATA OF REF. 14}

We have converted our raw 2D image of $\mathrm{O}^{3} \mathrm{P}_{2}$ atoms from the photodissociation of $\mathrm{C}_{6} \mathrm{H}_{12}-\mathrm{O}_{2}$ into a $1 \mathrm{D}$ curve. This conversion has been provided by projecting the crushed 2D image [left image on Fig. 1(d)] on an axis parallel (top panels) or perpendicular (bottom panels) to the laser polarization direction. The resulting 1D curves are shown on the right side of Fig. 7 and the data from Ref. 14 are shown on the left side of the figure. The good resolution of the velocity map images allows us to observe the angular anisotropy of the product $\mathrm{O}$ atoms even after reduction to a $1 \mathrm{D}$ curve. The features due to channel $\mathrm{C} 1$ are revealed as shoulders on the velocity profile. The experimental scatter in the TOF data ${ }^{14}$ makes these shoulders difficult to observe.
${ }^{1}$ D. H. Parker, Acc. Chem. Res. 33, 563 (2000).

${ }^{2}$ A. J. Blake and D. G. McCoy, J. Quant. Spectrosc. Radiat. Transf. 38, 113 (1987).

${ }^{3}$ S. Koda and K. Sugimoto, J. Photochem. Photobiol. C 4, 215 (2003).

${ }^{4}$ Y. Oshima, Y. Okamoto, and S. Koda, J. Phys. Chem. 99, 11830 (1995).

${ }^{5}$ J. Goodman and L. E. Brus, J. Chem. Phys. 67, 1482 (1977).

${ }^{6}$ B. Coquart and D. A. Ramsay, Can. J. Phys. 64, 726 (1986).

${ }^{7}$ S. Koda and H. Kajihara, Bull. Chem. Soc. Jpn. 70, 1225 (1997).

${ }^{8}$ P. Bernath, M. Carleer, S. Fally, A. Jenouvrier, A. C. Vandaele, C. Hermans, M. F. Merienne, and R. Colin, Chem. Phys. Lett. 297, 293 (1998).

${ }^{9}$ D. F. Evans, J. Chem. Soc. 1953, 345.

${ }^{10}$ V. R. Blok, O. L. Lebedev, and N. G. Mekhryakova, Dokl. Akad. Nauk SSSR 249, 633 (1979).

${ }^{11}$ G. Y. Zelikina, V. V. Bertsev, A. P. Burtsev, and M. B. Kiseleva, Opt. Spectrosc. 81, 685 (1996); G. Y. Zelikina, M. B. Kiseleva, A. P. Burtsev, and V. V. Burtsev, ibid. 85, 520 (1998).

${ }^{12}$ Shardanand, Phys. Rev. 186, 5 (1969).

${ }^{13}$ G. DeBoer and M. A. Young, J. Chem. Phys. 106, 5468 (1997).

${ }^{14}$ G. DeBoer, A. P. Prince, and M. A. Young, J. Chem. Phys. 115, 3112 (2001).

${ }^{15}$ B. F. Parsons and D. W. Chandler, J. Phys. Chem. A 107, 10544 (2003).

${ }^{16}$ A. Giardini Guidoni, A. Paladini, M. Veneziani, R. Naaman, and T. M. Di Palma, Appl. Surf. Sci. 154-155, 186 (2000).

${ }^{17}$ A. T. J. B. Eppink and D. H. Parker, Rev. Sci. Instrum. 68, 3477 (1997).

${ }^{18}$ D. Chestakov, S.-M. Wu, G. Wu, D. H. Parker, A. T. J. B. Eppink, and T. N. Kitsopoulos, J. Phys. Chem. A 108, 8100 (2004).

${ }^{19}$ D. W. Chandler and P. L. Houston, J. Chem. Phys. 87, 1445 (1987).

${ }^{20}$ V. Dribinski, A. Ossadtchi, V. A. Mandelshtam, and H. Reisler, Rev. Sci. Instrum. 73, 2634 (2002).

${ }^{21}$ P. C. Cosby and D. L. Huestis, J. Chem. Phys. 97, 6108 (1992).

${ }^{22}$ B. Buijsse, W. J. van der Zande, A. T. J. B. Eppink, D. H. Parker, B. R. Lewis, and S. T. Gibson, J. Chem. Phys. 108, 7229 (1998).

${ }^{23}$ Unlike the present study, none of the previous studies (Refs. 13-16) were able to detect $\mathrm{O}$ atoms from the photodissociation of free $\mathrm{O}_{2}$ at the concentrations used for the cluster study.

${ }^{24}$ G. A. Bogdanchikov, A. V. Baklanov, and D. H. Parker, Chem. Phys. Lett. 376, 395 (2003).

${ }^{25}$ T. N. Dunning, Jr., J. Chem. Phys. 90, 1007 (1989).

${ }^{26}$ J. M. L. Martin and A. Sunderman, J. Chem. Phys. 114, 3408 (2001).

${ }^{27}$ A. Bergner, M. Dolg, W. Kuechle, H. Stoll, and H. Preuss, Mol. Phys. 80, 1431 (1993).

${ }^{28}$ EMSL Basis Set Library: http:/www.emsl.pnl.gov:2080/forms/ basisform.html

${ }^{29}$ M. J. Frisch, G. W. Trucks, H. B. Schlegel et al., GAUSSIAN 98, Revision A.9, Gaussian, Inc., Pittsburgh, PA, 1998.

${ }^{30}$ K. M. Ervin, I. Anusiewicz, P. Skurski, J. Simons, and W. C. Lineberger, J. Phys. Chem. A 107, 8521 (2003).

${ }^{31}$ T. G. Slanger and P. C. Cosby, J. Phys. Chem. 92, 267 (1988).

${ }^{32}$ B. F. Minaev, K. V. Mikkelsen, and H. Ågren, Chem. Phys. 220, 79 (1997).

${ }^{33}$ G. Y. Zelikina, M. B. Kiseleva, M. V. Buturlimova, and A. P. Burtsev, Opt. Spectrosc. 93, 214 (2002)

${ }^{34}$ R. S. Mulliken, J. Am. Chem. Soc. 74, 811 (1952).

${ }^{35}$ V. Aquilanti, D. Ascenzi, D. Cappeletti, M. de Castro, and F. Pirani, J. Chem. Phys. 109, 3898 (1998).

${ }^{36}$ D. J. Lavrich, M. A. Buntine, D. Serxner, and M. A. Johnson, J. Chem. Phys. 99, 5910 (1993).

${ }^{37}$ L. Dinu, G. C. Groenenboom, and W. J. van der Zande, J. Chem. Phys. 119, 8864 (2003).

${ }^{38}$ Y. F. Zhu and E. R. Grant, J. Phys. Chem. 97, 9582 (1993).

${ }^{39}$ CRC Handbook of Chemistry and Physics, 77th ed. edited by David R. Lide (CRC, Boca Raton, Fl, 1996).

${ }^{40}$ B. H. J. Bielski and J. M. Gebicki, J. Am. Chem. Soc. 104, 796 (1982).

${ }^{41}$ C. G. Bailey, D. J. Lavrich, D. Serxner, and M. A. Johnson, J. Chem. Phys. 105, 1807 (1996).

${ }^{42}$ P. Lin and R. R. Lucchese, J. Chem. Phys. 114, 9350 (2001).

${ }^{43}$ A. T. J. B. Eppink, D. H. Parker, M. H. M. Janssen, B. Buijsse, and W. J. van der Zande, J. Chem. Phys. 108, 1305 (1998).

${ }^{44}$ P. Y. Cheng, D. Zhong, and A. H. Zewail, J. Chem. Phys. 105, 6216 (1996).

${ }^{45}$ M. Tadjeddine, J. P. Flament, and C. Teichtel, Chem. Phys. 118, 45 (1987).

${ }^{46}$ G. Herzberg, Electronic Spectra and Electronic Structure of Polyatomic Molecules (Van Nostrand, Princeton, 1966). 